\title{
Genetic interplay between transcription factor Pou4f1/Brn3a and neurotrophin receptor Ret in retinal ganglion cell type specification
}

Vladimir Vladimirovich Muzyka $a^{1,2^{*}}$ and Tudor Constantin Badea1, $3^{*}$ (D)

\begin{abstract}
Background: While the transcriptional code governing retinal ganglion cell (RGC) type specification begins to be understood, its interplay with neurotrophic signaling is largely unexplored. In mice, the transcription factor Brn3a/ Pou4f1 is expressed in most RGCs, and is required for the specification of RGCs with small dendritic arbors. The Glial Derived Neurotrophic Factor (GDNF) receptor Ret is expressed in a subset of RGCs, including some expressing Brn3a, but its role in RGC development is not defined.

Methods: Here we use combinatorial genetic experiments using conditional knock-in reporter alleles at the Brn3a and Ret loci, in combination with retina- or Ret specific Cre drivers, to generate complete or mosaic genetic ablations of either Brn3a or Ret in RGCs. We then use sparse labelling to investigate Brn3a and Ret gene dosage effects on RGC dendritic arbor morphology. In addition, we use immunostaining and/or gene expression profiling by RNASeq to identify transcriptional targets relevant for the potential Brn3a-Ret interaction in RGC development.

Results: We find that mosaic gene dosage manipulation of the transcription factor Brn3a/Pou4f1 in neurotrophic receptor Ret heterozygote RGCs results in altered cell fate decisions and/or morphological dendritic defects. Specific RGC types are lost if Brn3a is ablated during embryogenesis and only mildly affected by postnatal Brn3a ablation. Sparse but not complete Brn3a heterozygosity combined with complete Ret heterozygosity has striking effects on RGC type distribution. Brn3a only mildly modulates Ret transcription, while Ret knockouts exhibit slightly skewed Brn3a and Brn3b expression during development that is corrected by adult age. Brn3a loss of function modestly but significantly affects distribution of Ret co-receptors GFRa1-3, and neurotrophin receptors TrkA and TrkC in RGCs.
\end{abstract}

Conclusions: Based on these observations, we propose that Brn3a and Ret converge onto developmental pathways that control RGC type specification, potentially through a competitive mechanism requiring signaling from the surrounding tissue.

Keywords: Cell type specification, Retinal Ganglion Cell, Neurotrophic Signal, Transcription, Pou4f1, Ret

*Correspondence: vladimirv.muzyka@gmail.com; badeatc@mail.nih.gov; badeatc@unitbv.ro

${ }^{1}$ Retinal Circuit Development \& Genetics Unit,

Neurobiology-Neurodegeneration \& Repair Laboratory, National Eye Institute, NIH, Bethesda, MD, USA

Full list of author information is available at the end of the article

\begin{abstract}
Introduction
Retinal Ganglion Cells (RGCs) - the output neurons of the vertebrate retina - relay visual information to distinct projection areas in the brain. Currently, mouse RGCs are subdivided into about 50 types based on classification criteria including morphological, functional, and molecular parameters $[7,8,11,12,27,40,75,87,92,96]$. The developmental mechanisms orchestrating the differentiation of RGC types involve transcription factors
\end{abstract} original author(s) and the source, provide a link to the Creative Commons licence, and indicate if changes were made. The images or other third party material in this article are included in the article's Creative Commons licence, unless indicated otherwise in a credit line to the material. If material is not included in the article's Creative Commons licence and your intended use is not permitted by statutory regulation or exceeds the permitted use, you will need to obtain permission directly from the copyright holder. To view a copy of this licence, visit http://creativecommons.org/licenses/by/4.0/. The Creative Commons Public Domain Dedication waiver (http://creativeco mmons.org/publicdomain/zero/1.0/) applies to the data made available in this article, unless otherwise stated in a credit line to the data. 
(TFs) in combination with extracellular signaling. Within the retina, Atoh7/Math5 $[16,64,103]$ is required but not sufficient for neuronal precursors to commit to the RGC fate. Downstream of Atoh7, postmitotic TFs determine general traits of neuronal morphology and functional characteristics - in RGCs this group includes the three members of the Pou4f family, namely Pou4f1/Brn3a, Pou4f2/Brn3b, and Pou4f3/Brn3c [5, 7, 35, 38, 93, 105107]. Brn3a transcription is initiated after that of Brn3b (embryonic day 13.5 - E13.5 vs embryonic day 11.5 E11.5), acts downstream of Brn3b in the developmental transcriptional program, and was initially considered to function redundantly with Brn3b [83].

Deletion of Brn3a in mice leads to early postnatal lethality caused by somatosensory system and brainstem nuclei abnormalities, with no gross perturbations in the retina at this stage of development $[76,106]$. Using a conditional alkaline phosphatase (AP) reporter allele knocked-in to the Brn3a locus (Brn3a $a^{C K O A P}$ ) we demonstrated that Brn3a-expressing RGCs laminate in the outer strata $(\sim 70 \%)$ of the inner plexiform layer (IPL) of the retina. In this allele, the coding exons of the Brn3a gene can be removed using Cre recombination and replaced with the AP reporter, resulting in a loss of function (KO) knock-in allele (Brn3a ${ }^{\mathrm{AP}}$ ). Loss of Brn3a before the actual onset of locus expression results in a shift towards bistratified arbor morphologies and general decrease of RGC numbers by approximately $30 \%[5,7,93]$. This reduction is mostly explained by a loss of RGCs with small dendritic arbor areas and dense multistratified lamination pattern - ON and OFF $\beta$ RGCs. Comparison of wild type and Brn3a ${ }^{\mathrm{AP} / \mathrm{WT}}$ RGCs (effectively Brn3a het $=\mathrm{Brn} 3 \mathrm{a}^{\mathrm{KO} /}$ ${ }^{W T}$ ), show that removal of one copy of Brn3a either early in development or in the adult, does not significantly

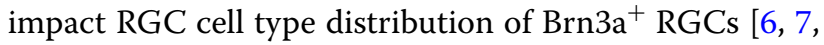
85, 93]. RNA deep sequencing of affinity-purified early postnatal Brn3a $\mathrm{a}^{\mathrm{AP} / \mathrm{KO}}$ (effectively Brn3a null $=\mathrm{Brn} 3 \mathrm{a}^{\mathrm{KO} /}$ $\mathrm{KO})$ RGCs revealed potential transcriptional targets for Brn3a regulation of cell type development [78, 92]. However, the developmental stage at which Brn3a is necessary for specification of ON and OFF $\beta$ RGCs is not known.

Amongst the neurotrophic cues required for neuronal development and specification, target derived neurotrophin (NT) and glial derived neurotrophic factor (GDNF) families of ligands play a major role. Components of receptor complexes for NTs contain members of distinct molecular families such as Trk, $\mathrm{p} 75^{\mathrm{NTR}}$ and sortilin [19, 37, 42, 43]. Neurotrophin receptors are also expressed in rodent RGCs during development $[66,92]$ and development of dendrites and axons and physiological maturation of RGC is modulated by neurotrophin-3 (NT-3), brain derived neurotrophic factor (BDNF), and neurotrophin receptors, TrkB and $p 75^{\mathrm{NTR}}[17,24,25,62$,
$65,71-73,89]$. Not much is known about the effects of Glial family ligands (GFLs) and their receptors in RGC development and specification. The GDNF family of neurotrophins contains four members - GDNF, artemin, neurturin, and persephin. Four co-receptors, "GDNF family receptor- $\alpha$ " (GFR $\alpha$ 1-4) attached to the cell membrane through a Glycosyl Phosphatidylinositol (GPI) anchor have selective affinity to the four ligands [2, 33, 80, 99]. The tyrosine kinase Ret co-receptor is required for downstream signaling through GFR $\alpha$. Ret ablation phenotype is characterized by dramatic abnormalities of kidney formation, severely affected sympathetic ganglia, and defects in specific pain and touch somatosensory receptor cells, and megacolon (Hirschsprung disease) due to defects in the specification and migration of cells of the enteric nervous system $[34,39,67,68,81,100]$. GFR $\alpha 1$, GFR $\alpha 2$ and Ret are expressed in RGC subpopulations, however, no RGC phenotypes were reported in Ret or GFR mutants. Ret and Neurturin mutants affect photoreceptor light responses by impairing synapses between photoreceptors, bipolar and horizontal cells [15]. Ret is dynamically expressed in specific retinal cell populations, beginning with RGCs (E13 - 14.5), followed by Horizontal (E17) and Amacrine (P1) cells [4, 82, 85]. In the adult retina, Ret is co-expressed with Brn3a predominantly in three mono- and two bistratified subtypes of RGCs, with Brn3b - in four mono- and two bistratified subtypes, and with Brn3c - in a single monostratified subpopulation. Of interest, Brn3a and Ret are co-expressed in $\mathrm{ON}$ and OFF $\beta$ RGCs [85].

In the current study, we use a $R e t^{\operatorname{CreER} t 2}$ allele to induce sparse random recombination in Cre-dependent histochemical reporters targeted at the Brn3a and Rosa26 loci, to visualize RGC dendritic arbor morphologies in sparse

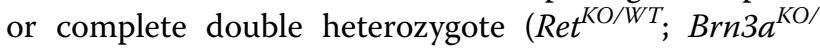
$\left.{ }^{W T}\right)$ retinas at different developmental stages. In addition, we reveal the effects of knocking out Brn3a at important developmental timepoints on RGC subtype distribution. Finally, using immunostaining in Ret or Brn3a complete retinal knock-outs, we assess the potential crosstalk between transcriptional and neurotrophic mechanisms in RGCs. We find that Brn3a is required for the development of at least two monostratified RGC subtypes during embryonic and perinatal stages. However, the most striking finding is the specific effect of embryonic sparse double-heterozygosity on cell type specification in monoand bistratified RGCs and on dendritic morphology in a subset of bistratified RGCs.

\section{Materials and methods} Mouse lines and crosses

Mouse lines carrying Rosa26 $6^{i A P}$ [6], Brn3a ${ }^{K O}$ [106], $B r n 3 a^{C K O A P}$ [5], Ret ${ }^{\text {CreERt2 }}$ [67], Rax:Cre [59] and 
$\operatorname{Ret}^{\text {CKCFP }}[100]$ alleles were previously described. In the $B r n 3 a^{K O}$ allele, the entire open reading frame of Brn3a is deleted and replaced with a Neo cassette. $\mathrm{Brn} 3 a^{\mathrm{KO} /}$ KO mice are perinatal lethal, while $B r n 3 a^{K O / W T}$ mice are viable and breed normally [106]. In the Brn3a $a^{C K O A P}$ allele the two coding exons of Brn3a are appended with a $(3 \times$ SV40) transcriptional STOP and flanked by loxP sites [5] and the cDNA of the histochemical reporter Alkaline Phosphatase (AP) is inserted after the 3' loxP site. Cre mediated recombination results in ablation of the Brn3a open reading frame (ORF) coupled with expression of the AP cDNA under the control of the endogenous regulatory elements of the Brn3a locus $\left(\mathrm{Brn} 3 \mathrm{a}^{\mathrm{AP}}\right)$. The Rosa26 ${ }^{i A P}$ reporter locus expresses AP ubiquitously in a Cre dependent manner [6]. The $\operatorname{Ret}^{C K-}$ ${ }_{C F P}$ conditional minigene allele includes the complete human Ret cDNA flanked by loxP sites knocked-in into exon 1 of the mouse Ret gene and followed by the Cyan Fluorescent Protein (CFP) cDNA [100]. The unrecombined locus expresses the full human Ret ORF, while Cre mediated recombination ablates Ret, and replaces it with CFP, generating a Ret null allele. The BAC transgenic mouse line Rax:Cre contains Cre recombinase controlled by the mouse Rax gene locus [59], and expresses Cre in the anterior eye field, beginning with E9. The Ret ${ }^{\text {CreERt2 }}$ allele contains the CreERt2 (tamoxifen-dependent Cre activity) coding sequence knockedin in the first exon of the Ret gene [67], resulting in a Ret null allele.

To understand the cell-autonomous effects of losing one or both copies of Brn3a at different time points

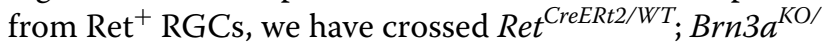
${ }^{W T}$ males x Brn $3 a^{C K O A P / C K O A P}$ females resulting in RetCreERt2/WT; Brn $3 a^{C K O A P / W T}$ and Ret ${ }^{C r E E R t 2 / W T} ; B r n 3 a^{C K O A P /}$ $K O$ pups. To achieve random sparse recombination and AP expression, we induced Cre recombinase by intraperitoneal (i.p.) injection of 4-hydroxytamoxifen (4-HT) at postnatal day 22 (P22 - adult, 50-100 $\mu \mathrm{g} 4-\mathrm{HT}$ ), postnatal day 0 (P0 pups, 2.5-5 $\mu \mathrm{g} 4-\mathrm{HT}$ ), or at embryonic day 15 (E15 embryos, delivered i.p. to the mother, $250 \mu \mathrm{g}$ 4-HT) (Fig. $1 \mathrm{a}, \mathrm{b})$. To study the effects of complete double-heterozygosity (Brn3a ${ }^{\mathrm{KO} / \mathrm{WT}}$; $\operatorname{Ret}^{\mathrm{KO} / \mathrm{WT}}$ ) on RGC dendritic morphology, we crossed $\operatorname{Ret}^{\mathrm{CreERt} 2 / W T}$; $B r n 3 a^{K O / W T}$ males x ROSA26 ${ }^{A P / A P}$ females to get Ret $^{\text {Cre- }}$ ERt2/WT; Brn3a $a^{K O / W T} ;$ ROSA26 $6^{A P / W T}$ and Ret $t^{\text {CreERt2/WT; }}$ $B r n 3 a^{W T / W T} ; R O S A 26^{A P / W T}$ pups. Cre recombination and AP expression were induced by i.p. injections of 4-HT to the mother at E15 (250 $\mu \mathrm{g}$ 4-HT, Fig. $1 \mathrm{c}, \mathrm{d})$. For each genotype, and age of $4 \mathrm{HT}$ treatment, retinas from at least three animals of either sex were analyzed at two months after injection, with the exception of P0 induced Ret ${ }^{C r e-}$ $E R t 2 / W T ; B r n 3 a^{C K O A P / W T}$ mice, where only two animals were analyzed. a
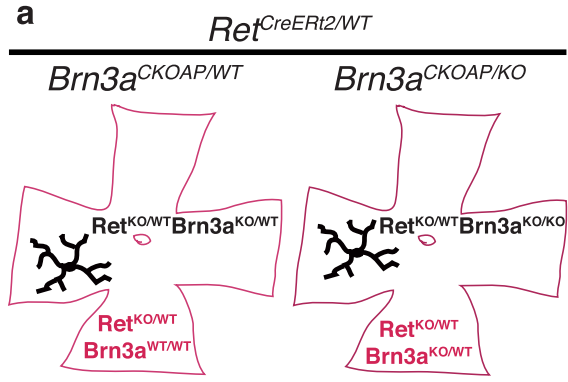

b
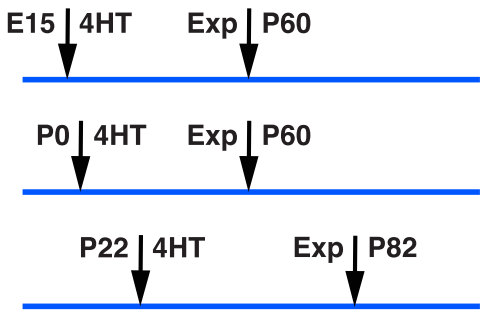

C

RetCreERt2WT ; ROSA26 $6^{A P N T}$

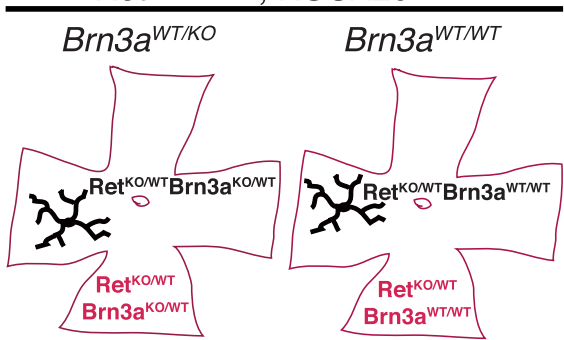

d E15 $14 \mathrm{HT} \quad \operatorname{Exp} \mid \mathrm{P} 60$

Fig. 1 Experimental Timelines of Sparse Random recombination in

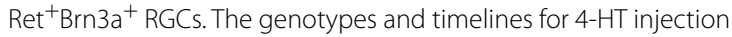
refer to experiments described in Figs. 2, 3, 4, 5, 6 and 7. a Retinas

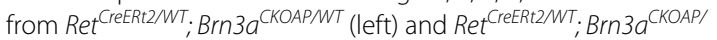

${ }^{K O}$ (right) mice, were injected with 4-HT to induce sparse random recombination. Recombined cells (black arbors) are either $\operatorname{Re}^{\mathrm{KO} /}$ ${ }^{\mathrm{WT}}$; Brn3a ${ }^{\mathrm{KO} / \mathrm{NT}}$ (Ret ${ }^{\mathrm{CreER} 2 / \mathrm{NT}}$; Brn3a ${ }^{\mathrm{AP} / \mathrm{WT}}$ ) on a Ret ${ }^{\mathrm{KO} / \mathrm{NT}}$; Brn3a ${ }^{\mathrm{WT} /}$ WT background (left) or Ret ${ }^{\mathrm{KO} / W T}$; Brn3 $3 \mathrm{a}^{\mathrm{KO} / \mathrm{KO}}$ (Ret ${ }^{\text {CreERt2/WT; }}$ Brn3a ${ }^{\text {AP/ }}$ ${ }^{\mathrm{KO}}$ ) on a Ret ${ }^{\mathrm{KO} / \mathrm{NT}} ; \mathrm{Brn} 3 \mathrm{a}^{\mathrm{KO} / \mathrm{NT}}$ background (right). b Timelines for experiments in a. Injections were i.p. either to the pregnant female (for E15), to postnatal pups (P0) or adult mice (P22). Retinas from E15 or P0 inductions were stained at two months postnatal (P60), while P22 induced animals were analyzed at 2 months post injection (P82). c Sparse random recombination approach in Ret ${ }^{\text {CreERt2 } 2 W T \text {; }}$

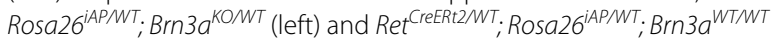
(right) retinas. After 4-HT induced recombination, RGCs are labelled by the Rosa26 $6^{\text {APNT }}$ allele, but preserve the same genotype as the surrounding tissue: $\operatorname{Ret}^{\mathrm{KO} / \mathrm{NT}} ; \mathrm{Brn} 3 \mathrm{a}^{\mathrm{KO} / \mathrm{WT}}$ (left) or Ret ${ }^{\mathrm{KO} / \mathrm{WT}} ; \mathrm{Brn} \mathrm{a}^{\mathrm{WT} /}$ WT (right). d Timelines for experiments in c. Injections at E15 were i.p. to the pregnant female, and retinas of offspring were stained at two months postnatal (P60)

To study potential transcriptional regulation of Brn3a via Ret signaling we crossed Rax:Cre; Ret ${ }^{\text {CKCFP/ }}$ ${ }^{W T}$ males $\mathrm{x}$ Ret ${ }^{\text {CKCFP/CKCFP }}$ females resulting in Rax:Cre; 
$\operatorname{Ret}^{C K C F P / W T}$ (full-retina Ret-heterozygote) and Rax:Cre; Ret ${ }^{\text {CKCFP/CKCFP (full-retina Ret-knockout) offspring. To }}$ study potential Brn3a transcriptional regulation of Ret, GFR $\alpha$ and Trk receptors, we crossed Rax:Cre; $B r n 3 a^{K O /}$ WT males x Brn3a CKOAP/CKOAP females to get Rax:Cre; $B r n 3 a^{C K O A P / W T}$ (full-retina Brn3a-heterozygote) and Rax:Cre; Brn3a ${ }^{C K O A P / K O}$ (full-retina Brn3a-knockout) offspring. For these experiments, tissues were harvested from mice of both sexes, at E15, P0, and between two and four months of age.

All mice were on C57/Bl6-SV129 mixed background. All animal procedures were approved by the National Eye Institute (NEI) Animal Care and Use Committee under protocol NEI640.

\section{AP histochemistry and morphometric analysis}

Mouse retinas were stained, processed, and imaged, and RGC dendritic arbors were traced and quantified as described previously [8, 9, 85]. Animals were anesthetized and fixed by intracardiac perfusion with $4 \%$
Paraformaldehyde (PFA). Retinas were dissected and flat mounted, heat inactivated in a water bath at $65{ }^{\circ} \mathrm{C}$ for one hour, and then AP histochemical stain developed. Color images of retina whole mounts and DIC grayscale image stacks (at $1 \mu \mathrm{m}$ z step) of individual RGC dendritic arbors were captured with a Zeiss Imager.Z2. Morphological characteristics were measured using ImageJ software as described in Fig. 2 and references [8, 85]. Relative lamination levels of dendritic arbors in the IPL were described by the lamination measurements in Figs. 3, 5 and 6, and oriented by the previously reported stratification levels of ON and OFF Starburst Amacrine Cells (SACs) and the borderline between ON and OFF sublaminae of the IPL, as inferred from the lamination of axon terminals of $\mathrm{ON}$ bipolar cells [77]. Neuronal reconstructions were made using Neuromantic (Darren Myat, http://www.readi ng.ac.uk/neuromantic) and projections were generated using a Matlab (Mathworks, Inc.) script [93]. Numbers of cells, mice and litters analyzed for each genotype combination and condition, are indicated in the legend to Fig. 7.

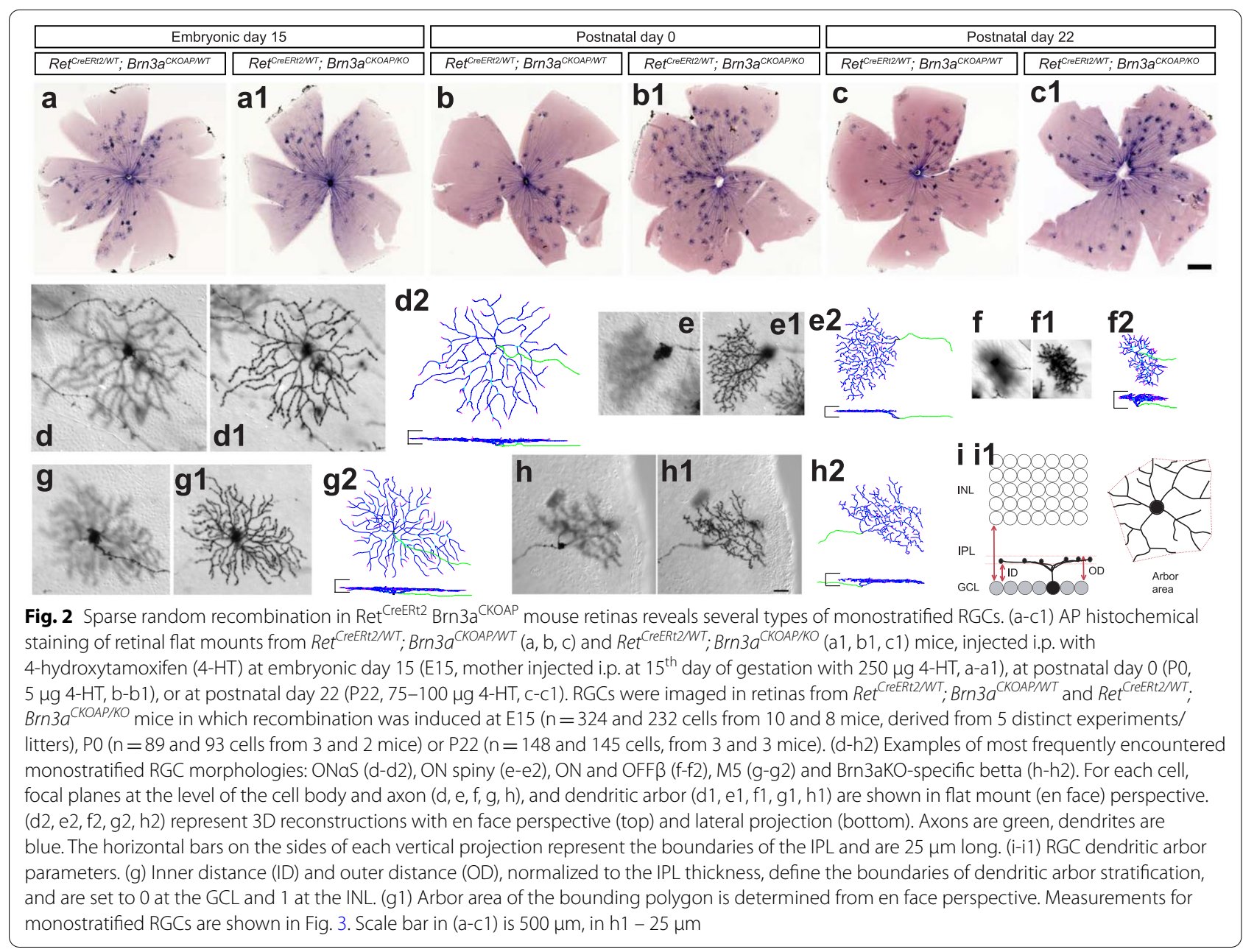




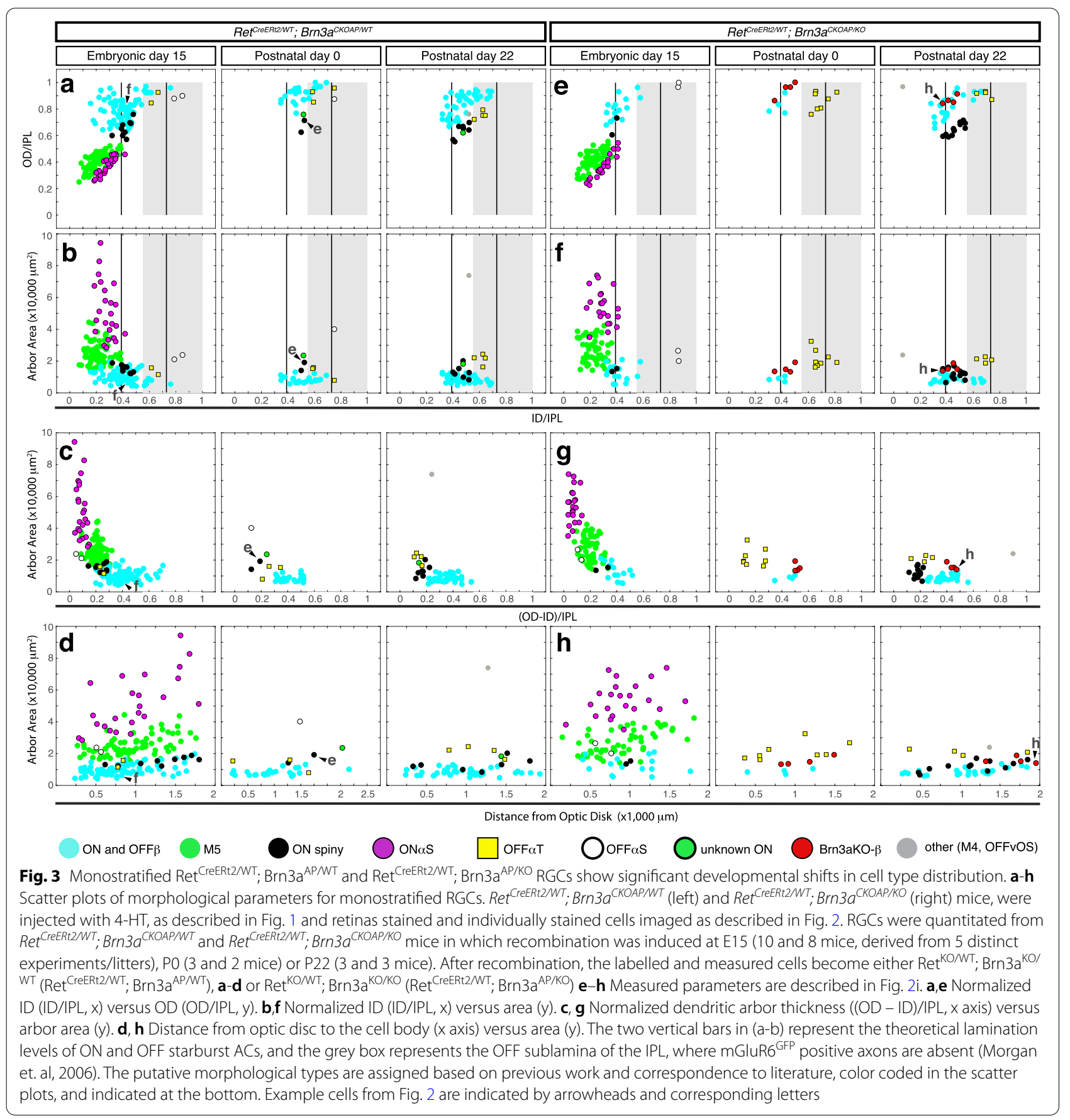

\section{Indirect immunofluorescence}

Retina vertical sections were processed and immunostained as previously described [5, 85, 93]. In brief, adult and postnatal day 0 (P0) retinas were fixed for $30 \mathrm{~min}$ in $2 \%$ paraformaldehyde, cryoprotected in OCT, and sectioned at $14 \mu \mathrm{m}$ thickness on a cryostat. For embryonic day E14.5 experiments, pregnant females from timed matings were anesthetized with ketamine-xylazine, embryos anesthetized on ice and decapitated, and whole heads were fixed for $3.5 \mathrm{~h}$ at $4{ }^{\circ} \mathrm{C}$, and cryoprotected in OCT. For each genotype and age, retinas from at least three different animals were sectioned and stained together on the same slide. Images (40x) were acquired using a Zeiss LSM700 confocal microscope and Zen software, or a Zeiss Imager. $\mathrm{Z} 2$ fitted with an apotome. Number of analyzed retinas 
and collected images are indicated in figure legends. Antibodies and dilutions used for analysis: 1:50 rabbit polyclonal anti-Brn3b generated in our lab [85], validated by western blotting and lack of reaction with KO tissues; 1:20 mouse monoclonal anti-Brn3a (Millipore, MAB1585, RRID: AB_94166, clone 5A3.2; [107], validated by western blott and lack of reactivity against KO tissues; 1:25 rabbit polyclonal anti-Ret (IBL, cat \# R787); 1:50 mouse monoclonal anti-alkaline phosphatase (VEB Gent, Belgium, E6 clone). 1:1000 chicken anti-GFP (used for detection of CFP protein; Abcam, ab13970, RRID: AB_300798). Alexa-Fluor conjugated Donkey polyclonal secondary antibodies were from Molecular Probes/Life Sciences and used at 1:300 dilution. TrkA: 1:40 Anti-TrkA antibody (R\&D Systems; AF1056, RRID: AB_2283049) was directed against mouse myeloma cell line NS0-derived recombinant rat TrkA Ala33- Pro418. The antibody shows $<5 \%$ cross reactivity with recombined human TrkA and $<1 \%$ cross reactivity with recombined mouse TrkB and TrkC. On Western blotting with rat striatum lysate, the antibody recognizes a $140-\mathrm{kDa}$ band specific for TrkA (Manufacturers information). TrkB 1:40 Anti-TrkB antibody (R\&D Systems; AF1494, RRID: AB_2155264) was produced against the extracellular domain (Cys32-His429) of recombinant mouse TrkB and detects mouse TrkB in direct ELISA and Western blotting and shows 25\% cross reactivity with human TrkB and $<2 \%$ cross reactivity with recombined rat TrkA and TrkC (Manufacturers information). TrkC 1:40 Anti-TrkC antibody (R\&D Systems; AF1404, RRID: AB_2155412) was raised in goat against the extracellular domain (Cys32Thr429) of recombinant mouse TrkC. The antibody has $<2 \%$ cross reactivity with recombinant TrkB or TrkA, as tested by ELISA and Western blotting with recombinant proteins. On Western blotting with mouse DRG lysate, it recognizes two bands of $100 \mathrm{kDa}$ and $145 \mathrm{kDa}$, the predicted molecular weight of TrkC (Manufacturers information). GFR $\alpha 1$ 1:20 Anti- GFR $\alpha 1$ antibody (R\&D Systems; AF560, RRID:AB_2110307) is a polyclonal goat antibody raised against NSO derived recombinant rat GFR $\alpha 1 /$ GDNF R 1 (aminoacids Asp25-Leu445), and affinity purified with the target antigen. Detects rat GFR $\alpha 1 /$ GDNF R $\alpha 1$ in direct ELISAs and $52 \mathrm{kD}$ band on western blots of rat brain. In direct ELISAs, approximately $20 \%$ crossreactivity with recombinant human GFR $\alpha 1$ is observed and less than $1 \%$ crossreactivity with recombinant mouse GFR $\alpha 2$ is observed (Manufacturers information. See also extensive reference list in RRID). GFR $\alpha 2$ 1:100 Anti- GFR $\alpha 2$ antibody (R\&D Systems; AF429, RRID: AB_2294621) is a polyclonal goat antibody raised against NSO-derived recombinant mouse GFR $\alpha-2 /$ GDNF R $\alpha-2$ (aminoacids
Ser22-Ser441), and affinity purified with the target antigen. Detects human and mouse GFR $\alpha-2 / G D N F ~ R \alpha-2$ in direct ELISAs and Western blots. In direct ELISAs and Western blots, less than $5 \%$ cross-reactivity with recombinant human GFR $\alpha-3$ is observed. (Manufacturers information. See also extensive reference list in RRID). GFR $\alpha 3$ 1:40 Anti- GFR $\alpha 3$ antibody (R\&D Systems; AF2645, RRID: AB_2110295) is a polyclonal goat antibody raised against $\mathrm{Sf}$-21derived recombinant mouse GFR $\alpha 3$ /GDNF R $\alpha 3$ (aminoacids Glu34-Arg379), and affinity purified with the target antigen. Detects mouse GFR $\alpha 3 /$ GDNF R $\alpha 3$ in direct ELISAs and Western blots. In direct ELISAs, approximately 10\% crossreactivity with recombinant human GFR $\alpha 3$ is observed and less than $2 \%$ crossreactivity with recombinant mouse (rm) GFR $\alpha 2$, rmGFR $\alpha$, and recombinant rat GFR $\alpha 1$ is observed. (Manufacturers information. See also extensive reference list in RRID).

\section{Statistical methods}

For RGC type distributions (Figs. 2, 3, 4, 5 and 6), data was collected from retinas from multiple animals (summarized in Fig. 7) for each treatment and genotype. Total numbers of measured cells are indicated in Fig. 7 legend, and ranged from 90 to more than 300. Differences in cell type distribution were assessed using the Chi-square method, and Chi Statistics and P values indicated in Supplementary Table 1. For Indirect Immunofluorescence Experiments (Figs. 8, 9 and 10, Supplementary Figs. 2 and 5), data was collected from at least three animals, and cells were counted in $6-20$ images for each genotype. Total numbers of measured cells are indicated in pie charts. Individual comparisons between groups of interest were performed using the Kolmogorov-Smirnov (KS2) test, and comparisons of marker distributions between different genotypes were assessed with the Chisquare method. All statistical parameters are indicated in Supplementary Table 2.

\section{Results}

Sparse random recombination in mice carrying Ret $^{\text {CreERt2 }}$ and Brn $3 a^{\text {CKOAP }}$ alleles induces mosaic gene dosage manipulations in RGCs

We had previously demonstrated that ablation of Brn3a before the onset of its expression (E12), results in essentially complete loss of RGC types with small, dense dendritic arbors (ON and OFF $\beta$ or "midget-like" RGCs), while other Brn3a ${ }^{+}$RGC types are only modestly affected $[5,7,93]$. ON and OFF $\beta$ RGCs, alongside several other cell types, are labelled when sparse random recombination is induced in adult $\operatorname{Ret}^{\mathrm{CreERt2} / W T} ; B r n 3 a^{C K O A P / W T}$ mice [85]. To explore the time points at which Brn3a is required for betta RGC development, we induced 


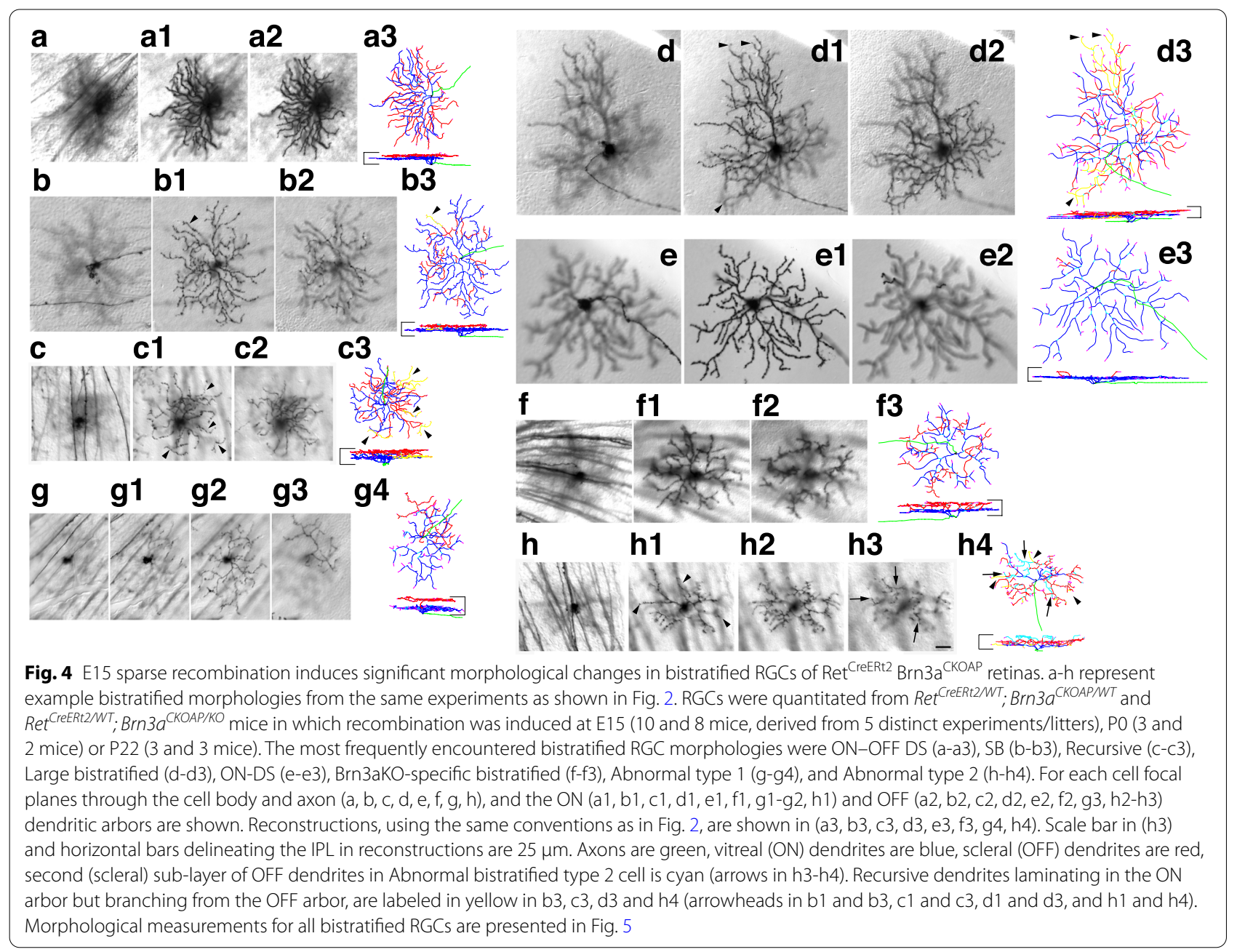

random sparse recombination in $\operatorname{Ret}^{\mathrm{CreERt2} / W T}$; Brn3a ${ }^{C K-}$ $O A P / W T$ and Ret $t^{\text {CreERt2/WT }}$; Brn3a $a^{C K O A P / K O}$ mice at E15, P0 and P22. Sparse recombination of the $B r n 3 a^{C K O A P}$ allele results in loss of one copy of the Brn3a gene by replacement with the AP reporter cDNA (Brn3a ${ }^{\mathrm{AP}}$, effectively a loss of function allele, Brn $3 \mathrm{a}^{\mathrm{KO}}$ ), which permits visualization of the recombined cells. This then means that AP positive cells (either Ret ${ }^{\operatorname{CreERt} 2 / \mathrm{WT}}$; Brn3 $\mathrm{a}^{\mathrm{AP} / \mathrm{WT}}$ or $\operatorname{Ret}^{\text {CreERt2/WT; Brn3a }}{ }^{\mathrm{AP} / \mathrm{KO}}$ ) carry one Brn3a gene copy less than the surrounding tissue. Given that the RetCreERt2 allele is a constitutive knock-in allele (the CreERt2 replaces the Ret endogenous transcription), sparsely labelled RGCs and surrounding tissue are both Ret heterozygotes $\left(\operatorname{Ret}^{\mathrm{KO} / \mathrm{WT}}\right)$. Therefore, upon recombination,

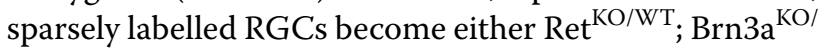
KO RGCs in a Ret ${ }^{\mathrm{KO} / \mathrm{WT}}$; Brn3a ${ }^{\mathrm{KO} / \mathrm{WT}}$ retinal background or Ret ${ }^{\mathrm{KO} / \mathrm{WT}}$; Brn3a ${ }^{\mathrm{KO} / \mathrm{WT}} \mathrm{RGCs}$ in a Ret ${ }^{\mathrm{KO} / \mathrm{WT}}$; Brn3a ${ }^{\mathrm{WT} /}$ ${ }^{\text {WT }}$ retinal background (Fig. 1 a, b, Figs. 2, 3, 4 and 5). In these experiments, the Brn3a gene dosages of labelled RGCs are different from the surrounding tissue. In order to study the effects of complete, homogenous double het-

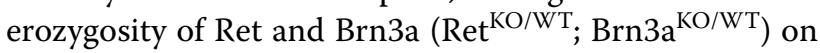
RGC development, we induced random sparse recombination in either $\operatorname{Ret}^{\operatorname{CreERt2} / W T}$; Rosa26 ${ }^{A P / W T} ; \mathrm{Brn} 3 a^{\mathrm{KO} /}$ ${ }^{W T}$ or Ret ${ }^{\text {CreERt2/WT }}$; Rosa $26^{A P / W T}$; Brn3a ${ }^{W T / W T}$ mice. In these experiments, labelled RGCs and surrounding retina have the same genotype (either $\operatorname{Ret}^{\mathrm{KO} / \mathrm{WT}} ; \mathrm{Brn} 3 \mathrm{a}^{\mathrm{KO} / \mathrm{WT}}$ or $\operatorname{Ret}^{\mathrm{KO} / \mathrm{WT}}$; Brn3a ${ }^{\mathrm{WT} / \mathrm{WT}}$, Fig. 1 c, d, Fig. 6). The study of adult RGC type distribution in full $\mathrm{Brn} 3 \mathrm{a}^{\mathrm{KO} / \mathrm{KO}}$ mutants is impossible, as they are dying at birth.

Although molecular characterizations of RGC type distributions are making great progress, neuroanatomically classifications are still the gold standard for RGC type classification. Classifications based on dendritic arbor morphology typically distinguish monostratified RGCs (whose dendrites constitute a contiguous arbor with respect to the vertical dimension of the retina "z dimension") and bistratified RGCs (in which dendrites laminate in clearly separatable, distinct sublaminae). We therefore present separately 


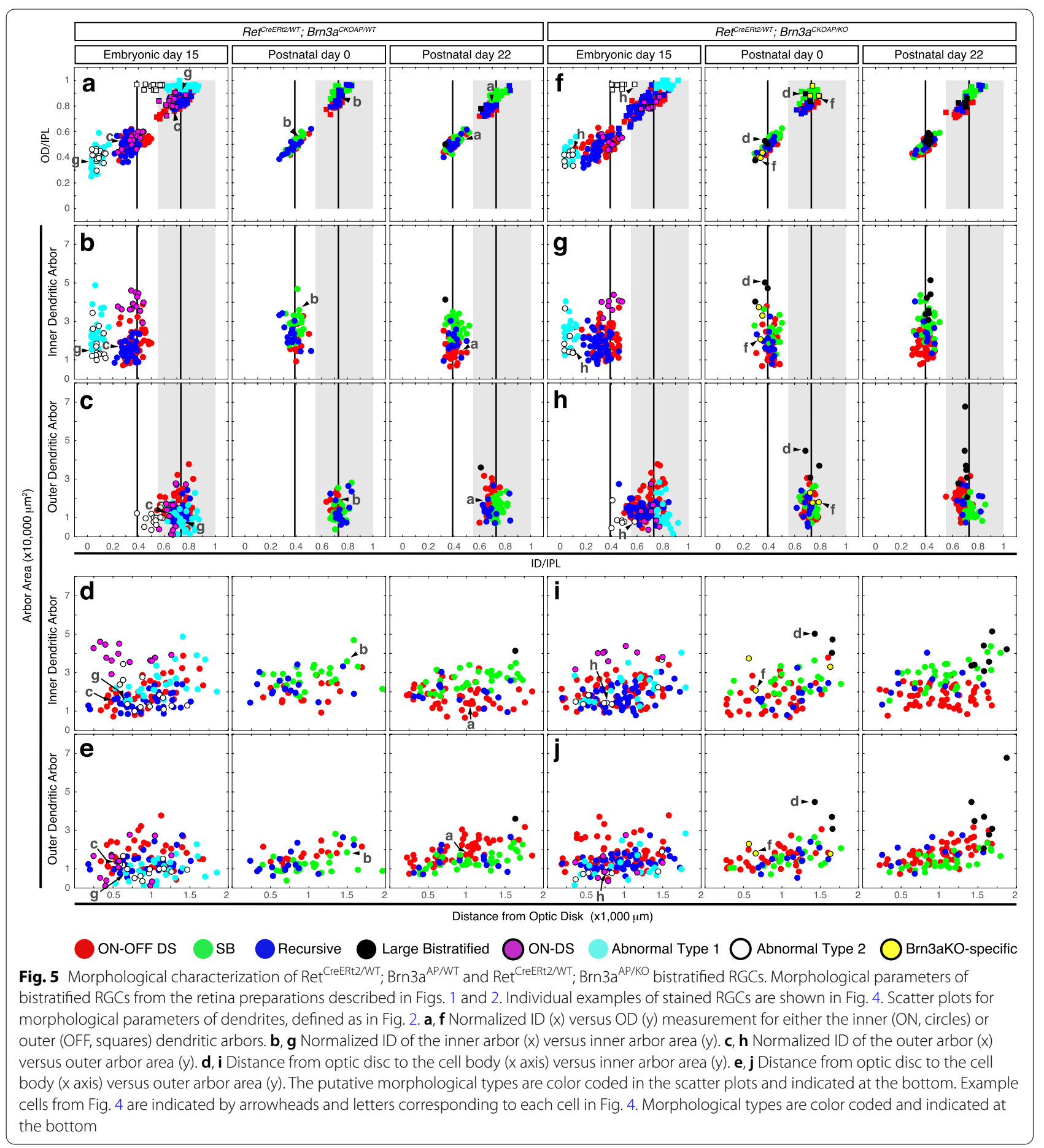

the distributions of monostratified (Figs. 2, 3) and bistratified RGCs (Figs. 4, 5) observed in the various genetic backgrounds, in order to better illustrate the morphological parameters that distinguish them. All samples were analyzed in the adult, when morphological criteria for individual cell types are clearly distinguishable, regardless of timing of induction of recombination. It should be noted that sparse random 
recombination will inherently result in varying numbers and cell type distributions of RGCs recombined in the individual animals. However, the RGC types dominating the cell types at each age and genotype are proportionally represented in each preparation (Supplementary Table 3).

\section{Cell type distribution of monostratified $\operatorname{Ret}^{+} \mathrm{Brn} \mathrm{a}^{+} \mathrm{RGCs}$ is significantly affected by developmental Brn3a gene dosage manipulations}

Sparse random recombination induced at E15, P0 or P22 results in labeling of RGCs at low densities permitting the clear visualization of individual dendritic arbors (Fig. 2 a-c1). As previously shown [85], Brn3a expression in adult retina (P22) predominantly intersects with Ret expression in three monostratified morphological RGC types (ON and OFF $\beta$ - "midget-like", Fig. $2 \mathrm{f}$-f2, and $\mathrm{ON}$ spiny, Fig. 2 e-e2, Fig. 3a-d, right hand panels). These morphologies are characterized by lamination ranging from the inner $30 \%$ of the IPL to the INL (Fig. 3a, b) and thick dendritic arbors spanning multiple lamina (Fig. 3c). Dendritic arbor areas in the flat mount perspective are amongst the smallest RGC arbors (Fig. 3b, c). In addition, isolated instances of several other monostratified cells were observed (Fig. 3a-d, right panel). A similar range of RGC types was observed when recombination was induced in Ret $^{\text {CreERt2/WT }}$; Brn3a ${ }^{C K O A P / W T}$ mice at P0 (Fig. 3a-d, compare middle to right panels). However, the overall monostratified RGC type distribution changed dramatically when recombination was induced at E15. Two cell types, On-Alpha-Sustained $=\mathrm{ON \alpha S}$ and Pixel Detectors (M5) (Fig. 2 d-d2, g-g2) made up more than $50 \%$ of monostratified cells (Fig. 3 a-d, left panel-E15, Table 2). These RGC types are characterized by dendritic arbors with large area and sharp lamination (Fig. 3b, c), that stratify between the GCL and the "ON" ChAT band of the IPL (Fig. 3a, b). Of note, $\mathrm{ON \alpha S}$ and M5 RGC morphologies are not observed in samples induced at P0 and P22, and have never been

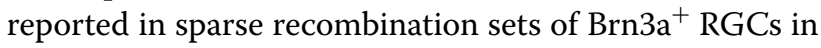
our previous studies $[5,7,85,93]$. Thus, these two morphologies appear unique to the Ret ${ }^{\mathrm{CreER} 2 / \mathrm{WT}} ; \mathrm{Brn} 3 \mathrm{a}^{\mathrm{AP} / \mathrm{WT}}$ RGC dataset with E15 induction.

\section{Embryonic and perinatal Cre activation results in loss of ON and OFF betta and ON spiny RGCs in Brn3a ${ }^{\text {CKOAP/ }}$ $\mathrm{KO}_{\text {retinas }}$}

We then analyzed subpopulations of Brn3a ${ }^{\mathrm{KO} / \mathrm{KO}} \mathrm{RGCs}$ generated by inducing sparse recombination at E15, P0, and P22 (adult). When recombination was induced in the adult, type distribution of Ret ${ }^{\text {CreERt2/WT }} ; \mathrm{Brn}^{\mathrm{AP}} \mathrm{aP}^{\mathrm{AP}}$ KO $\left(=\operatorname{Ret}^{\mathrm{KO} / \mathrm{WT}} ; \mathrm{Brn} \mathrm{a}^{\mathrm{KO} / \mathrm{KO}}\right)$ monostratified RGCs was

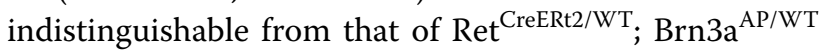
$\left(=\operatorname{Ret}^{\mathrm{KO} / \mathrm{WT}} ; \mathrm{Brn} \mathrm{a}^{\mathrm{KO} / \mathrm{WT}}\right)$ cells (Fig. $3 \mathrm{e}-\mathrm{h}$ vs. a-d, right hand panels, Table 2). However, when recombination was induced at P0-resulting in random sparse Brn3a loss of function soon after birth, monostratified Ret ${ }^{\mathrm{CreER} 2 / \mathrm{WT}}$; Brn3a ${ }^{\mathrm{AP} / \mathrm{KO}} \mathrm{RGCs}$ were clearly distinct from Ret ${ }^{\mathrm{CreERt} 2 /}$ ${ }^{W T}$; Brn3a ${ }^{A P / W T}$ RGC controls (Compare Fig. 3 e-h to a-d, middle panels, Table 2). The relative abundance of ON and OFF $\beta$ RGCs decreased considerably, and ON-Spiny neurons were completely missing. Additionally, we identified amongst Ret ${ }^{\mathrm{CreER} 2 / \mathrm{WT}}$; Brn3a ${ }^{\mathrm{AP} / \mathrm{KO}}$ RGCs induced at either P22 or P0 a minor subpopulation of RGCs with morphologies reminiscent of betta RGCs, but exhibiting somewhat larger areas and sparser dendritic arbors (Brn3aKO-specific betta RGC = Brn3aKO- $\beta$, Fig. 2 h-h2, Fig. 3e-h, middle and right scatter plots). RGCs with ON and OFF $\beta$ and ON Spiny morphologies are also underrepresented amongst $\operatorname{Ret}^{\mathrm{CreERt} 2 / \mathrm{WT}} ; \mathrm{Brn} 3 \mathrm{a}^{\mathrm{AP} / \mathrm{KO}}$ RGCs induced at E15, when compared to Ret ${ }^{\mathrm{CreER} 2 / \mathrm{WT}}$; Brn3a ${ }^{\mathrm{AP} / \mathrm{WT}}$ control RGCs while $\mathrm{ON \alpha S}$ and Pixel Detector (M5) RGCs are present in both backgrounds at similar levels (Fig. 3 e-h vs. a-d, left hand panels, Table 2).

\section{Dramatic shifts in bistratified RGC type distribution in Ret $^{\text {CreERt2/WT }}$; Brn3a ${ }^{\text {CKOAP/WT }}$ retinas with E15, vs. P0/P22 inductions}

In keeps with previously published data, the distribu-

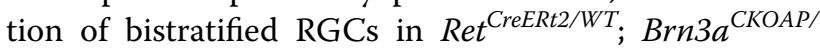
WT retinas with adult (P22) or perinatal (P0) induction of recombination consisted mostly of ON-OFF direction selective RGCs (ON-OFF-DS, Fig. 4 a-a3), Small Bistratified, (henceforth SB, Fig. 4 b-b3), and a significant number of bistratified RGCs with recursive dendrites (Fig. 4, c-c3, Fig. 5 a-c, middle and right panel). The inner

\footnotetext{
(See figure on next page.)

Fig. 6 Morphological characterization of RGCs from Ret ${ }^{C r e E R t 2 N T} ; B r n 3 a^{K O / W T} ; R O S A 26^{A P N T}$ and Ret ${ }^{C r e E R t 2 / W T} ; B r n 3 a^{W T W W T} ; R O S A 26^{A P N T}$ retinas. Cre WaS activated by i.p. administration of $250 \mu \mathrm{g} 4-\mathrm{HT}$ to mothers of the pups at gestational day 15 (E15 for pups), and RGCs visualized by recombination of the ROSA26 ${ }^{\mathrm{AP}}$ reporter. Labelled RGCs have the same Ret and Brn3a gene copy numbers as their respective retinas (either Ret ${ }^{\mathrm{KO} / W T}$; Brn3a ${ }^{\mathrm{KO} / \mathrm{WT}}$-left

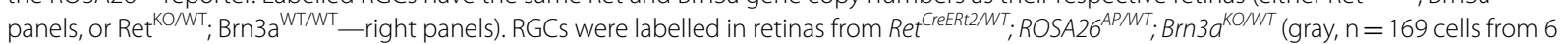
mice, derived from 3 distinct experiments/litters) and Ret ${ }^{\text {CreERt } 2 W T}$; ROSA26 ${ }^{A P N T}$; Brn $3 a^{\text {WT }}$ WT (white, $\mathrm{n}=138$ cells from 3 mice, derived from 2 distinct

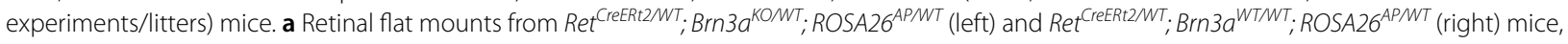
processed for AP histochemistry. Scale bar $500 \mu \mathrm{m}$. b-e Scatter plots for parameters of monostratified RGCs, defined and presented as in Figs. 2 and 3. f-j Scatter plots for parameters of bistratified RGCs as defined in Fig. 5. Example cells from Figs. 2 and 4 are indicated by arrowheads and letters corresponding to each cell in Fig. 2 - for monostratified RGCs, and in Fig. 4 - for bistratified RGCs
} 

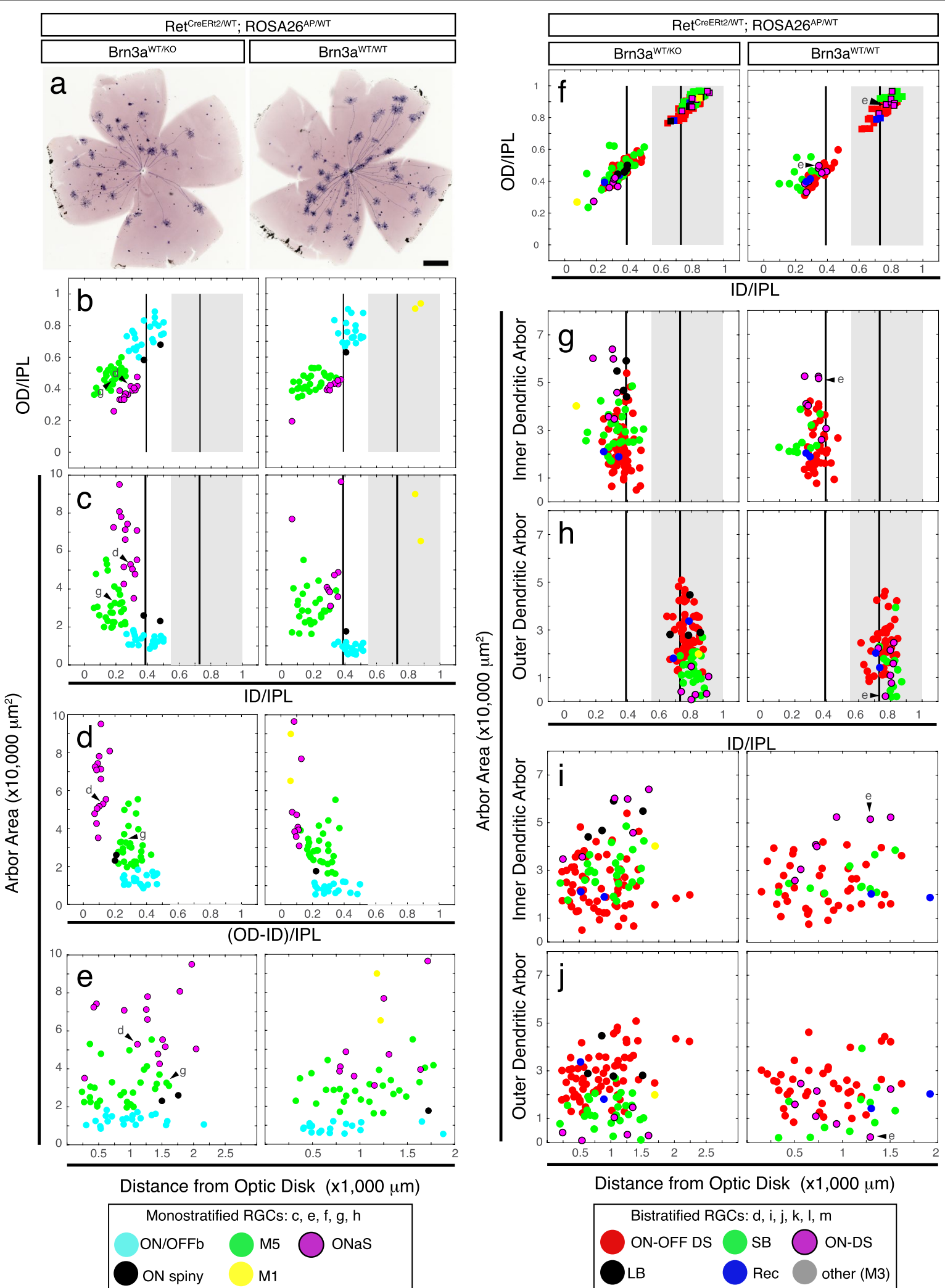

Distance from Optic Disk $(x 1,000 \mu \mathrm{m})$

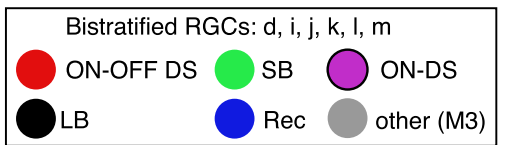

Fig. 6 (See legend on previous page.) 


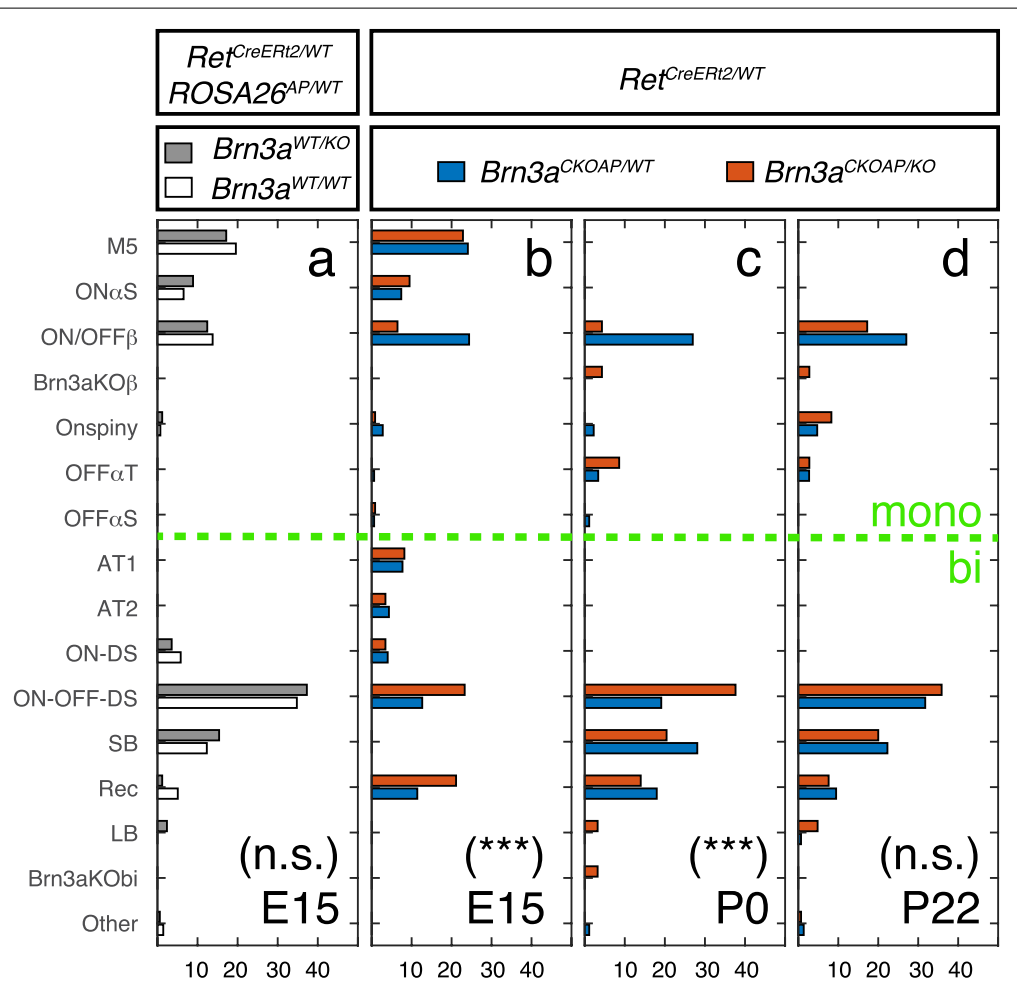

Fig. 7 Effects of Ret and Brn3a gene dosage on RGC type distribution. a-d represent summaries of data presented in Figs. 2, 3, 4, 5 and 6. RGC type is indicated on the $y$ axis. Frequency (\% total cells within genotype and age) is indicated on the $x$ axis. Monostratified and bistratified cell types are separated by the green stippled line. Cell types are arranged top to bottom according to the proximity of dendritic arbor to the GCL. RGC type definitions and relative frequencies are indicated in Tables 1 and 2. Cell type distributions for each retina are indicated in Supplementary Table 3. a Relative frequency of observed RGC types in retinas from Ret ${ }^{\text {CreERt2 } 2 W T}$; ROSA26 $6^{A P N T} ; B r n 3 a^{K O N T}$ (gray, $n=169$ cells from 6 mice, derived from 3 distinct experiments/litters) and Ret ${ }^{\text {CreERt2 } / W T}$; ROSA26 ${ }^{A P N T} ; B r n 3 a^{\text {WTWT }}$ (white, $\mathrm{n}=138$ cells from 3 mice, derived from 2 distinct experiments/litters) genotypes, as described in Fig. 6. The relative distributions of cell types in complete Brn3a ${ }^{\mathrm{KO} / \mathrm{NT}}$ (gray bars) vs. Brn3a ${ }^{\text {WT/WT }}$ (white bars) retinas were not statistically different from each other ( $X^{2}$ statistics, $p=0.328$, see Supplementary Table 1). b-d RGC type frequency in retinas from Ret ${ }^{\text {CreERt2 } N T \text {; }}$

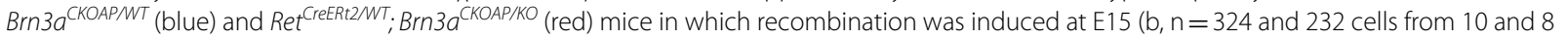
mice, derived from 5 distinct experiments/litters), PO ( $c, n=89$ and 93 cells from 3 and 2 mice) or P22 ( $d, n=148$ and 145 cells, from 3 and 3 mice), as described in Figs. 2, 3, 4 and 5. The relative distribution differences of cell types in sparse Brn3a ${ }^{\mathrm{KO} / \mathrm{WT}}$ (blue bars) vs. Brn3a ${ }^{\mathrm{KO} / \mathrm{KO}}$ (red bars) RGCs did not reach statistically significance at P22 $(p=0.071)$, but were highly significant at P0 $\left(p=3.9^{*} 10^{-5}\right)$ and E15 $\left(p=6^{*} 10^{-7}, x^{2}\right.$ statistics comparing the distribution of RGC types for each genotype, see Supplementary Table 1). Cell type distributions for sparsely recombined Brn3a ${ }^{\mathrm{KO} / \mathrm{NT}} \mathrm{RGCs}$ (blue bars) were not significantly different between P22 and P0 ( $p=0.231)$, but highly significant between P22 and E15 $\left(p=1.6^{*} 10^{-30}, X^{2}\right.$ statistics $)$

and outer dendritic arbor of these three cell populations are centered respectively on the $\mathrm{ON}$ and OFF starburst laminae (Fig. 5a-c), however they can be distinguished by smaller outer dendritic arbor areas for the SBs (Fig. 4 b-b3, Fig. 5a-c) and a high degree of recursive dendrites for recursive RGCs (Fig. $4 \mathrm{c} 3$, yellow dendrites, originating in the outer dendritic arbor and returning to the inner arbor). In addition, distance between inner and outer arbor are larger for SB and recursive RGCs compared to the ON-OFF DS RGCs (Fig. 4a-c3, Fig. 5a-c, middle and right pannel). SB morphologies were essentially missing, amongst E15-induced bistratified neurons, while three distinct morphological types, not observed in the samples induced at P0 and P22 made up sizeable fractions of bistratified neurons (AT1, AT2, ON-Direction
Selective $=$ ON-DS, Fig. 4 e-e3, g-g4, h-h4, Fig. 5 a-e left panels, Table 2). AT1 and AT2 are two unusual bistratified morphologies characterized by ON dendritic arbors which stratify in apposition to the GCL (normalized ID index is between $\sim 0$ and 0.2 , where 0 is GCL level, Fig. 5 $\mathrm{a}, \mathrm{b}$, left panels), while their OFF dendritic arbors laminate close to the INL (Fig. 5 a, c, left panels). In the case of AT1, the OFF arbor is relatively simple and derives in most cases via a single branch straight from the cell body. However, AT2 bistratified neurons have a thicker OFF dendritic arbor (in z dimension) (Fig. 5 a, c left panels), which can be occasionally resolved into two subarbors, creating the impression of a tri-stratified neuron (Fig. 4 h-h4). Morphologies similar to AT2 were recovered by random sparse recombination in wild type retina 
Table 1 RGC subtypes and their possible matches from EyeWire Museum. For each type we provide the closest correspondence in the EyeWire museum and physiology or anatomy literature, if available

\begin{tabular}{|c|c|c|}
\hline RGC subtype & \#-s of RGCs from EyeWire Museum & References \\
\hline \multicolumn{3}{|l|}{ Monostratified RGCs } \\
\hline ON alpha sustained & $8 \mathrm{w}(\mathrm{ONaS})$ & {$[61,84,101]$} \\
\hline M5 & $8 n, 9 n$ & {$[32,56,94,95]$} \\
\hline ON spiny & $6 s n$ & {$[13,55,86,90]$} \\
\hline ON $\beta$ & $63\left(\mathrm{~F}-\mathrm{mini}^{\mathrm{On}}\right), 5 \mathrm{ti}, 5 \mathrm{si}$ & {$[55,90,111]$} \\
\hline OFF $\beta$ & 2 an $\left(F-m i n i{ }^{o f f}\right)$ & {$[55,90,111]$} \\
\hline OFF transient & $4 \mathrm{i}, 40 \mathrm{n}, 40 \mathrm{w}, 30$ & {$[61,84]$} \\
\hline OFF sustained & 1no, 1ni, $1 \mathrm{wt}$ & {$[61,84]$} \\
\hline \multicolumn{3}{|l|}{ Bistratified RGCs } \\
\hline ON-OFF DS & 37c, 37d, 37r, 37v (On-Off DS) & {$[3,46,88,104]$} \\
\hline Small Bistratified (Supressed by contrast ?) & 7o(tOn DS), 81i, 82n & {$[28,70,98]$} \\
\hline Recursive & 72,73 & [7] \\
\hline Large Bistratified & $\mathrm{n} / \mathrm{a}$ & {$[7,85]$} \\
\hline ON-DS & 7id, 7ir, 7iv (sOn DS) & {$[108,109]$} \\
\hline Abnormal type 1 & $\mathrm{n} / \mathrm{a}$ & $\mathrm{n} / \mathrm{a}$ \\
\hline Tristratified (Abnormal Type 2) & 85 & {$[8]$} \\
\hline
\end{tabular}

(Badea et al. 2004 [8], Fig. 15 a), and resemble cell type 85 in the serially reconstructed dataset in the Eyewire Museum (http://www.museum.eyewire.org). However, we are not aware of any instances of AT1 morphologies in either repositories or previous literature. The ON-DS RGC, is, based on dendritic arbor areas and lamination, most likely the $\mathrm{ON}$ direction selective RGC, which is known to occasionally have smaller branches co-stratifying with the OFF ChAT band, and has been recorded in early embryonic induced $B r n 3 a^{C K O A P / W T}$ samples ([5, 7, 93], Fig. 4 e-e3, Fig. 5a-c, left side). Thus, analogous to monostratified RGCs, several unique bistratified morphologies appear in $\mathrm{Ret}^{\mathrm{CreERt2/WT}}$; Brn $3 a^{C K O A P / W T}$ retinas with E15 induced recombination, when compared to those recombined at adult (P22) or perinatal (P0) ages.

\section{Brn3a loss of function induces subtle effects in bistratified RGCs}

In our previous work, we had reported a moderate effect of Brn3a ablation on bistratified RGC morphology. Here we use sparse random recombination in the Ret $^{\text {CreERt2 }}$; Brn $3 a^{C K O A P}$ intersection to study the effect of Brn3a ablation on bistratified RGCs at several developmental stages. Bistratified Ret ${ }^{\mathrm{CreERt} 2 / \mathrm{WT}}$; Brn3a ${ }^{\mathrm{AP} / \mathrm{WT}}$

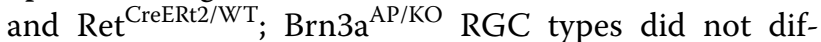
fer significantly when sparse random recombination was induced at P22, while only modest differences were observed in the P0 induced data set (Fig. 5, a-c vs $\mathrm{f}-\mathrm{h}$, middle and right plots, Table 2). The majority of bistratified RGCs labeled belonged to the ON-OFF DS,
SB, and Recursive Bistratified types. A few examples of Large Bistratified RGCs (LB, Fig. 4 d-d3) were observed specifically amongst P0 and P22 Ret ${ }^{\text {CreERt2/WT; }}{ }^{B r n 3 a^{A P /}}$ KO RGCs (Fig. $5 \mathrm{f}-\mathrm{h}$, middle and right panels). In addition, in P0 induced recombinations, a few instances of a Brn3aKO-specific subpopulation were recovered. These cells exhibit a simplified $\mathrm{ON}$ arbor from which relatively simple straight branches descend and form small tufts into the OFF lamina (Fig. $4 \mathrm{f}$-f3, Fig. $5 \mathrm{f}-\mathrm{h}$ middle panels), and resemble the ones previously described in early sparse recombination experiments [7]. The AT1 and AT2 morphologies are observed in the dataset induced at E15 in both Ret ${ }^{\text {CreERt2/WT }}$; Brn3a ${ }^{\mathrm{AP} / \mathrm{WT}}$ and Ret ${ }^{\mathrm{CreER} 2 / \mathrm{WT}}$; Brn3a ${ }^{\mathrm{AP} / \mathrm{KO}}$ RGCs with comparable frequencies (Fig. 5, f-h, left panels, Table 2).

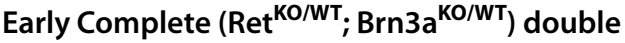 heterozygosity does not affect $\operatorname{Ret}^{+} \mathrm{RGC}$ type distribution}

Ret expression in the retina changes significantly between embryonic, postnatal and adult stages of development [85]. We had previously described the RGC type distribution in $\operatorname{Ret}^{\mathrm{CreERt2} / W T}$; ROSA26 ${ }^{A P / W T}$ mice in which random sparse recombination was induced at P14 and adult [85]. Is the dramatic shift in $\operatorname{Ret}^{+}{\mathrm{Brn} 3 \mathrm{a}^{+}}^{+} \mathrm{RGC}$ types observed in E15 random sparse recombination experiments due to developmental differences of expression intrinsic to the Ret locus? Alternatively, are the shifts in RGC types due to a genetic interaction between Brn3a and Ret in the double heterozygote mice? To further explore these questions, we induced random sparse recombination in $\operatorname{Ret}^{\mathrm{CreERt} 2 / W T}$; 


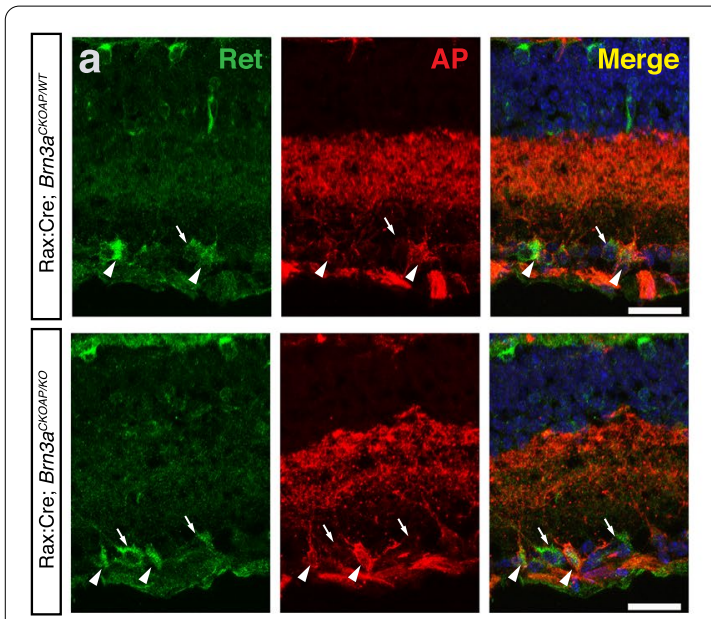

Rax:Cre; Brn3a ${ }^{C K O A P W T} \quad$ Rax:Cre; Brn3a $a^{\text {CKOAP/KO }}$

b
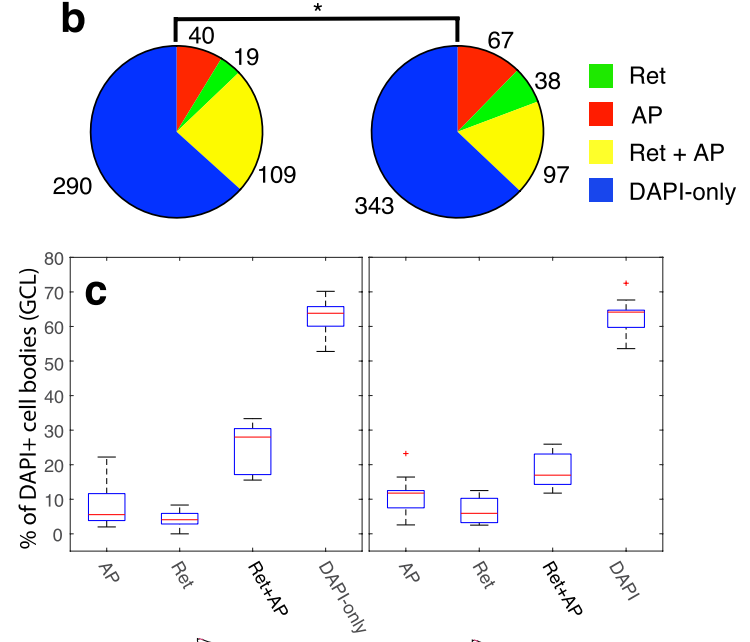

d
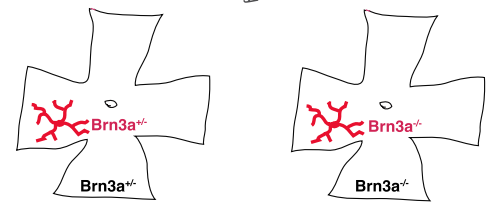
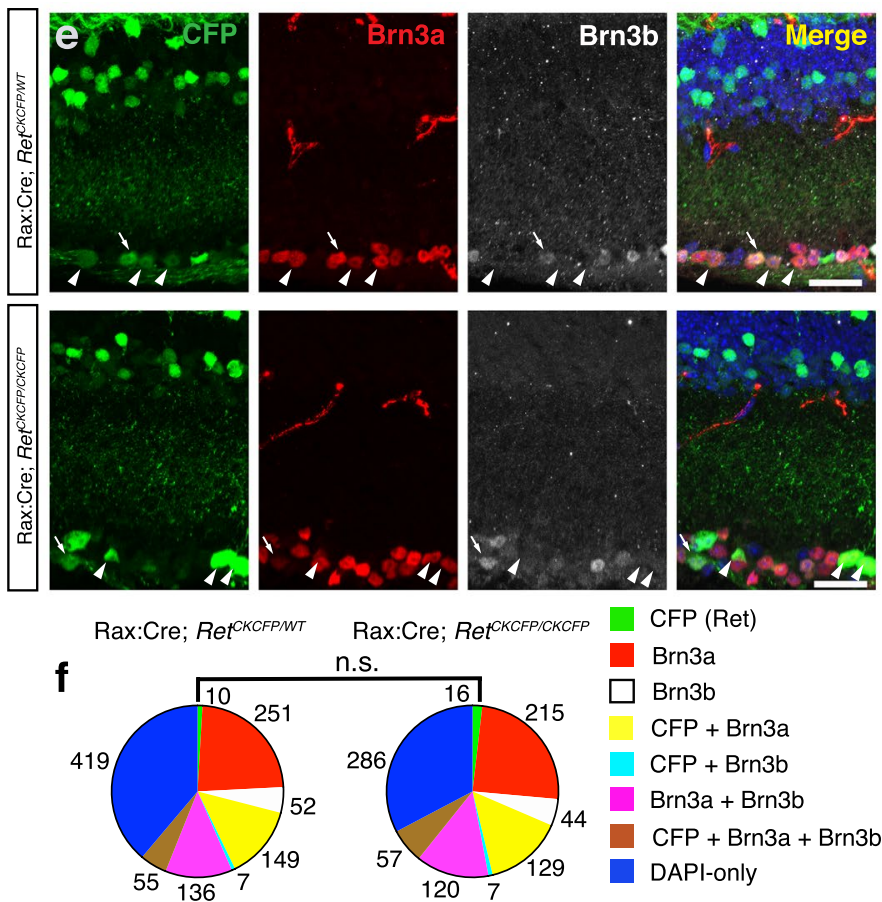

Rax:Cre; Ret ${ }^{C K C F P / C K C F P}$ n.s.

CFP (Ret)

Brn3a
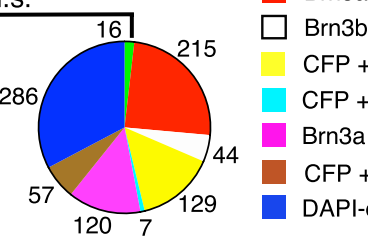

$\mathrm{CFP}+\mathrm{Brn} 3 \mathrm{a}$

CFP $+B r n 3 b$

Brn3a+Brn3b

CFP + Brn3a + Brn3b

DAPI-only

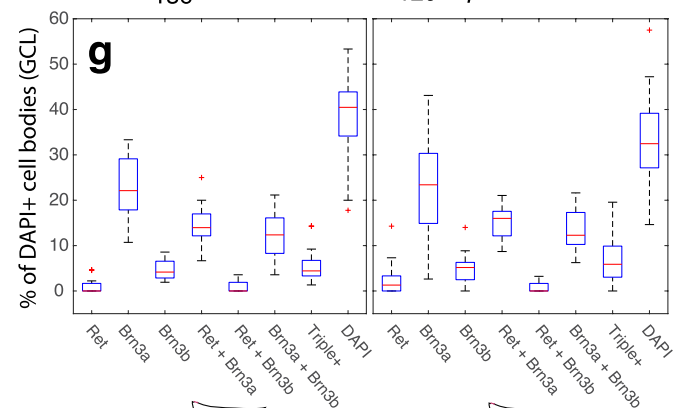

h
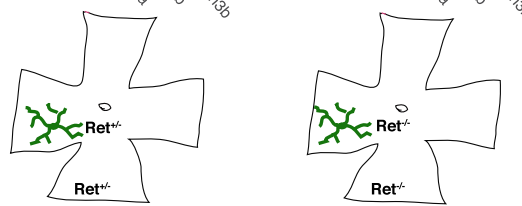

Fig. 8 Effects of complete loss of function of Brn3a or Ret on RGCs. a Immunostaining of retina sections from Rax:Cre; Brn3aCKOAPNT (top row) and Rax:Cre; Brn3a ${ }^{C K O A P K O}$ (bottom row) mice, using anti-Ret (green), anti-alkaline phosphatase (anti-AP, red) antibodies, and DAPI nuclear stain. Arrows indicate Ret-only-positive cells, arrowheads indicate Ret $^{+} \mathrm{AP}^{+}$double-labeled cells. $\mathbf{b}$ Pie-charts and (c) box-plots representing proportions of different cell categories according to the expression of Ret and AP in Rax:Cre; Brn3a $a^{\text {CKOAPNT }}$ (left) and Rax:Cre; Brn3a ${ }^{\text {CKOAP/KO (right) }}$ animals. Total number of cells for each category are presented next to the pie-chart markers, and data spread for each category is shown in the boxplots, expressed as percent total DAPI positive cells. $\mathbf{d}$ RGCs (in red) and their respective retinas (in black) have matching genotypes in both Rax:Cre; Brn3a ${ }^{C K O A P / N T}$ (left) and Rax:Cre; Brn3a ${ }^{\text {CKOAP/KO }}$ (right) animals. e Immunostaining of sections through retinas from Rax:Cre; Ret ${ }^{\text {CKCFP } W T}$ (top

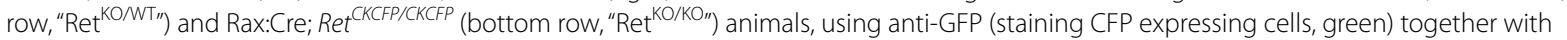
anti-Brn3a (red), anti-Brn3b (white) antibodies, and DAPI nuclear stain. Arrowheads indicate $\left(\mathrm{CFP}^{+} \mathrm{Brn}^{3} \mathrm{a}^{+}\right)$double-positive cells, and arrows indicate $\left(\mathrm{CFP}^{+} \mathrm{Brn} \mathrm{a}^{+} \mathrm{Brn}^{\mathrm{B}} \mathrm{b}^{+}\right)$triple-labeled cells respectively. (f) Pie charts and $(\mathbf{g})$ box-whiskers plots representing quantitation of immunostaining sections from Ret ${ }^{\mathrm{KO} / \mathrm{WT}}$ (left) and Ret ${ }^{\mathrm{KO} / \mathrm{KO}}$ (right) mice. Total number of cells for each category is presented next to the pie-chart markers. $\mathbf{h}$ CFP-positive RGCs

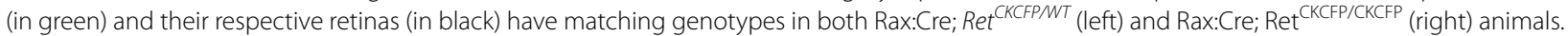
For each genotype in (a-c and e-g), sections from at least 3 different animals were stained and 9-20 images were quantified. For Box-Whisker plots, the red lines represent the median, the rectangles represent the interquartile interval, and the whiskers the full range of observations. Red crosses are outliers. Significance levels: ${ }^{*}, p<0.05 ;{ }^{* *} p<0.01 ;{ }^{* *} p<0.001 ;$ n.s. $>=0.05$. Total number of mice, images and cells in Supplementary Table 2. Scale bar in (a) and (e) is $25 \mu \mathrm{m}$ 
ROSA26 ${ }^{A P / W T} ; B r n 3 a^{K O / W T}$ and $R e t^{\mathrm{CreERt2} / W T} ; \operatorname{ROSA}^{\mathrm{AP} /}$ ${ }^{W T}$; Brn3a ${ }^{W T / W T}$ mice at E15 and analyzed RGC type distribution in adult (> P60) mice (Fig. 1 c, d, Fig. 6a). The profiles of mono- and bistratified RGCs is similar in complete $B r n 3 a^{W T / W T}$ and complete Brn3a $a^{K O / W T}$ retinas (Fig. 6) and the distribution of monostratified RGC types induced at E15 in $\operatorname{Ret}^{\mathrm{CreERt} 2 / W T} ; \operatorname{ROSA26^{AP/WT}}$ mice was not affected by Brn3a dosage and resembled the RGC types identified in $R e t^{C r e E R t 2 / W T} ; B r n 3 a^{C K O A P / W T}$ mice induced at the same age, with small variations in M5 and betta cell numbers (Fig. 6 b-e, Table 2). However, bistratified RGCs induced at E15 in either Ret ${ }^{\mathrm{CreERt2} / W T}$; ROSA26 ${ }^{A P / W T}$; Brn3a ${ }^{W T / W T}$ or RetCreERt2/WT; ROSA26 ${ }^{A P / W T}$; Brn3a $a^{K O / W T}$ backgrounds were restricted to the previously described major types $(\mathrm{ON}-$ OFF DS, SB, Recursive, ON-DS and LB), and no instances of AT1 and AT2 RGCs were observed (Fig. $6 \mathrm{f}-\mathrm{j}$ ). This distribution is consistent with the one seen for Ret ${ }^{C r e E R t 2 / W T}$; $B r n 3 a^{C K O A P / W T}$ or $\operatorname{Ret}{ }^{C r e E R t 2 / W T}$; ROSA26 $6^{A P / W T}$ mice upon adult inductions. Thus, complete heterozygous Brn3a loss did not affect the pattern of Ret expression in RGCs at E15. Moreover, the expression profile of Ret amongst RGC types, as measured by induction of $R e t^{C r e E R t 2 / W T}$ in the background of the ROSA26 ${ }^{A P / W T}$ allele, does not change dramatically from E15 to adult (compare Fig. 6 to Parmhans 2018, [85], Figs. 6 h and 7 c-d).

\section{Brn3a gene dosage and dynamic Ret expression distinctly affect RGC development}

We summarize the RGC type distribution changes produced by Brn3a gene dosage manipulations in $\operatorname{Ret}^{\mathrm{KO} / \mathrm{WT}}$ neurons across all ages and genotypes in Fig. 7 (statistical comparisons in Supplementary Table 1). For each recombination age, relative frequencies for all cell types are plotted side by side for Ret ${ }^{\mathrm{KO} / \mathrm{WT}} ; \mathrm{Brn} \mathrm{a}^{\mathrm{KO} / \mathrm{WT}}$ (blue) and $\operatorname{Ret}^{\mathrm{KO} / \mathrm{WT}}$; Brn3a ${ }^{\mathrm{KO} / \mathrm{KO}}$ (red) RGCs (Fig. 7b-d, summarized from data presented in Figs. 2, 3, 4 and 5), or Ret ${ }^{\mathrm{KO} / \mathrm{WT}} ; \mathrm{Brn} \mathrm{a}^{\mathrm{KO} / \mathrm{WT}}$ (gray) and Ret ${ }^{\mathrm{KO} / \mathrm{WT}}$; Brn3a $\mathrm{a}^{\mathrm{WT} / \mathrm{WT}}$ (white) RGCs (Fig. 7a, based on data in Fig. 6). These cell type distributions are based on the adult patterns of dendritic arbor anatomies, as it is essentially impossible to identify the RGC types at earlier, immature stages of development.

\section{Dynamic developmental effect of random sparse heterozygosity}

Sparse random Brn3a heterozygosity induced by P0 recombination in $\operatorname{Ret}^{\mathrm{CreERT2} / W T} ; \operatorname{Brn} 3 a^{C K O A P / W T}$ retinas does not produce significant changes when compared to the adult pattern (compare blue bars in Fig. 7c and d, $p=0.231, \chi^{2}$ statistics, Supplementary Table 1), and both distributions are indeed in good agreement with previously published sparsely labelled Ret ${ }^{\mathrm{CreERT}}{ }^{2 \mathrm{WT}}$; Brn3 $\mathrm{a}^{\mathrm{AP} / \mathrm{WT}}$ or Brn3a ${ }^{\mathrm{AP} / \mathrm{WT}}$ RGCs $[5,7,85,93]$. However, E15 recombination induced in $\operatorname{Ret}^{\mathrm{CreERT2} / W T} ; \mathrm{Brn} 3 \mathrm{a}^{\mathrm{CK}-}$ $O A P / W T$ retinas produces a dramatic shift in RGC type distribution relative to P0 and P22 (compare blue bars in Fig. $7 \mathrm{~b}-\mathrm{d}, p=1.6^{*} 10^{-30}, \mathrm{X}^{2}$ statistics, Supplementary Table 1). The major differential is produced by the presence in the E15-induced dataset of five RGC types that are not observed in the P0 or P22-induced samples: M5, ONaS, ON-DS, AT1 and AT2. In addition, SB RGCs, that represent $22-28 \%$ of RGCs in the P0 and P22 datasets, are absent from the E15 sample (Fig. 7b-d, Table 2). While ON-DS RGCs have previously been shown to be Brn3a positive, four of the five cell types which are unique to the Ret ${ }^{\mathrm{CreER} 2 / \mathrm{WT}}$; Brn3a ${ }^{\mathrm{AP} / \mathrm{WT}}$ RGC population induced at $\mathrm{E} 15(\mathrm{ON \alpha S}, \mathrm{M} 5$, AT1, AT2) were never previously observed in sparsely labelled Brn3a ${ }^{\mathrm{AP} / \mathrm{WT}}$ RGCs [5, $7,85,93]$. In addition, the ON dendritic arbors of these 4 cell types are laminated within the IPL in close proximity to the GCL, a sublamina that is typically not labelled when dendritic arbors of the entire Brn3a $\mathrm{a}^{\mathrm{AP} / \mathrm{WT}} \mathrm{RGC}$ population are labelled by E9.5 recombination $([5,78,93]$ and Fig. 8a). Thus, it appears that a subset of E15 induced

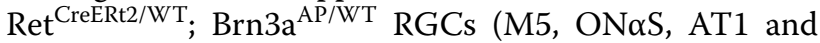
AT2) constitute a distinct RGC subpopulation that typically does not express Brn3a or exhibits morphological differences from previously described $\mathrm{Brn}_{3} \mathrm{a}^{+}$RGCs.

\section{Developmental dynamics of Ret expression in RGCs}

The complete expression profile of Ret in RGCs at E15 can be derived from the Ret ${ }^{\text {CreERt2/WT }}$; ROSA26 ${ }^{A P /}$ ${ }^{W T}$; Brn $3 a^{W T / W T}$ experiments, in which recombination was induced at E15 (Figs. 6 and 7 a, white bars).

\footnotetext{
(See figure on next page.)

Fig. 9 Full retinal Brn3a KO significantly affects distribution of GFRa Ret co-receptors in RGCs. Retinal sections from Rax:Cre; Brn3a $a^{C K O A P / W T}$ (a,c,e) and Rax:Cre; $B r n 3 a^{C K O A P / K O}(\mathbf{b}, \mathbf{d}, \mathbf{f})$ mice, were stained using antibodies against GFRa1 (a-b),aGFRa2 (c-d) or aGFRa3 (e-f) (green, left panels) in conjunction with AP (red, middle panels) and DAPI (right panels show three-color merged image). Arrowheads indicate single labelled cells (AP or GFRa) and arrows point to double labeled cells (GFRa ${ }^{+} \mathrm{AP}^{+}$). Total numbers of quantified cells are represented as pie charts in $\mathrm{g}$, i and $\mathrm{k}$ and indicated next to each sector. Significance levels for the comparison between the distributions for Rax:Cre; Brn3a ${ }^{C K O A P}$ WT (left) and Rax:Cre; $B r n 3 a^{C K O A P / K O}$ mice are calculated using the Chi-square statistic. Chi statistic, $p$-values and degrees of freedom are indicated in Supplementary Table 2. Box-plots representing proportions of different cell categories according to the expression of each GFRa and AP are shown in $h$, j an I, expressed as percent total DAPI positive cells in the GCL. Significance levels for differences between Rax:Cre; Brn3a $a^{C K O A P / W T}$ (left) and Rax:Cre; $B r n 3 a^{C K O A P / K O}$ (right) retinas were calculated using Kolmogorov-Smirnoff 2 test. For each genotype and antibody, sections from $2-3$ different animals were stained and 8-10 images were quantified (Supplementary Table 2). For Box-Whisker plots, the red lines represent the median, the rectangles represent the interquartile interval, and the whiskers the full range of observations. Outliers are indicated by red crosses. Scale bar in (f) is $25 \mu \mathrm{m}$
} 

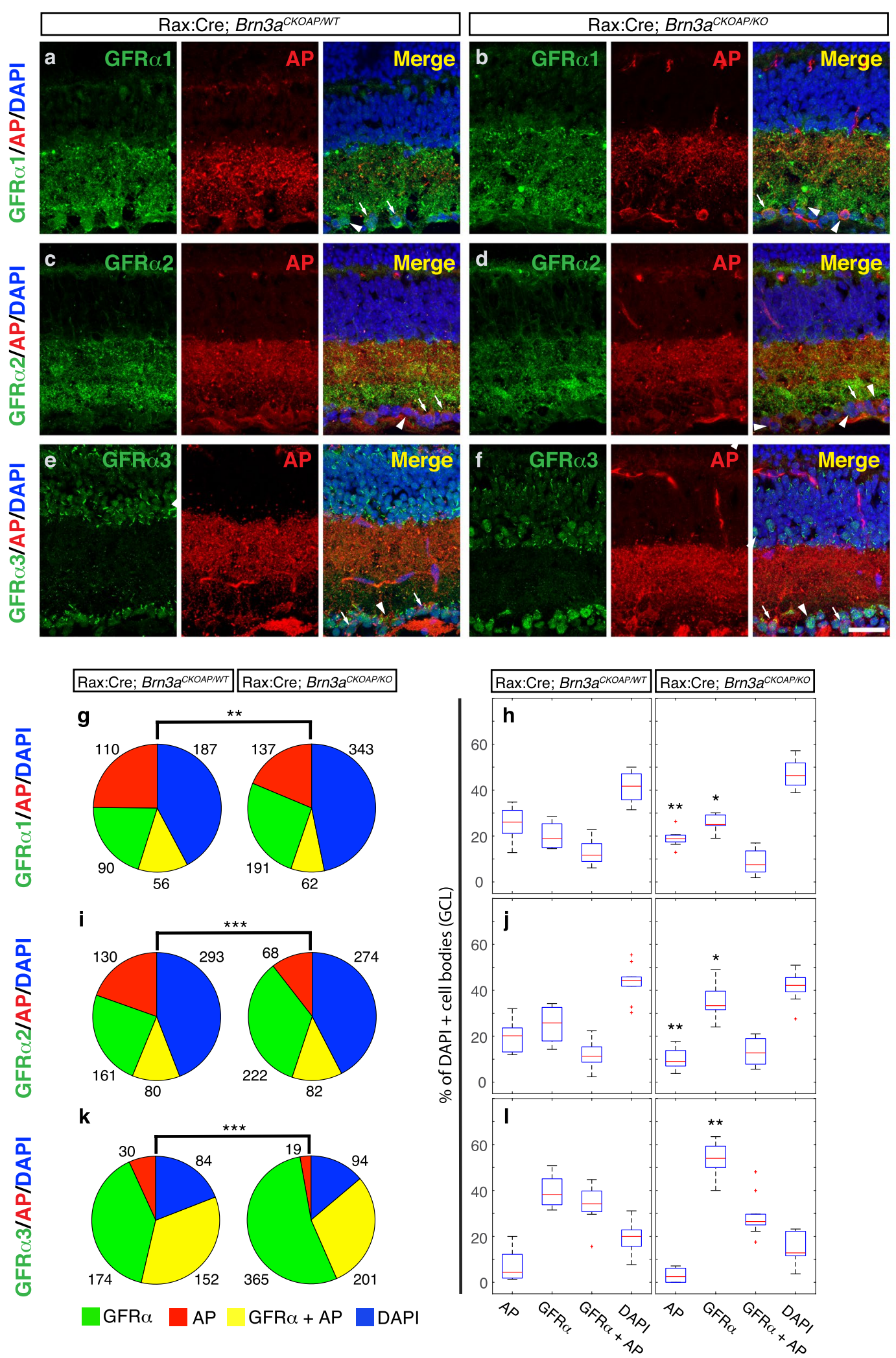

Fig. 9 (See legend on previous page.) 
This distribution closely resembles the one described for adult retinas of Ret ${ }^{\mathrm{CrEERt2} / W T}$; ROSA26 ${ }^{A P / W T}$ mice in which recombination was induced in the adult or P14 [85], with the notable addition of ON-DS and Recursive RGCs in the E15 dataset. Thus, the selective presence of ON-DS RGCs in the E15 -induced Ret ${ }^{\text {CreERT2/WT; }}$ $B r n 3 a^{C K O A P / W T}$ data (but not in P0 or P22 induced samples of the same genotype), could be explained by the differential expression of Ret in ON-DS RGCs at E15 vs. P22. Interestingly, removing one Brn3a copy from the whole tissue (germline heterozygosity), in $\mathrm{Ret}^{\mathrm{Cre}-}$ $E R t 2 / W T$; ROSA26 ${ }^{A P / W T}$; Brn $3 a^{K O / W T}$ mice (Fig. 7a, gray bars), does not affect the cell type distribution when compared to the Ret ${ }^{\mathrm{CreERt2} / W T}$; ROSA26 ${ }^{A P / W T}$; Brn $3 a^{W T \prime}$ ${ }^{W T}$ controls (Fig. 7a, white bars, $p=0.328, \chi^{2}$ statistics, Supplementary Table 1).

\section{Complete vs. Sparse double heterozygosity}

The sparse removal of one Brn3a copy from Ret ${ }^{\mathrm{KO} /}$ ${ }^{\text {WT }}$ RGCs at E15 in Ret ${ }^{C r e E R T 2 / W T}$; Brn3a ${ }^{C K O A P / W T}$ retinas (Fig. 7b, blue bars), results in a RGC type distribution that is distinct from the one observed in complete Brn3a heterozygotes (Ret ${ }^{\text {CreERt2/WT }}$; ROSA26 $6^{A P / W T}$; Brn $3 a^{K O / W T}$, Fig. 7a, gray bars) or Brn3a wild types $\left(\right.$ Ret $^{\mathrm{CreERt2} / W T} ; \operatorname{ROSA26^{AP/WT}} ; \mathrm{Brn} 3 a^{W T / W T}$, Fig. 7a, white bars). AT1 and AT2 RGCs are present and SB RGCs are absent in sparse Brn3a heterozygotes in contrast to complete heterozygotes or wild types. Thus, at least four RGC types that appear in the E15-induced in Ret $^{\text {CreERT2/WT }}$; Brn $3 a^{C K O A P / W T}$ retinas (Fig. $7 \mathrm{~b}$, blue bars) compared to P0 or P22 (Fig. 7c, d, blue bars) cannot be explained by a dynamic shift in Ret expression between embryonic and postnatal ages: based on previous studies, M5 and $\mathrm{ON \alpha S}$ are not part of the Brn3a ${ }^{+}$ RGC repertoire, regardless of induction age, while AT1 and AT2 are not seen amongst any of the other

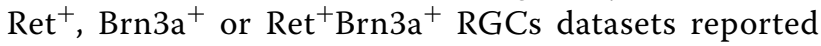
here or in previous publications. In addition, although SB RGCs are part of the Ret $^{+}$expression profile at
E15 (Fig. 7a), and the Ret ${ }^{+} \mathrm{Brn} \mathrm{a}^{+}$datasets at P0 and P22 (Fig. 7c and 7d), they are selectively missing from $\operatorname{Ret}^{\mathrm{KO} / \mathrm{WT}} ; \mathrm{Brn} \mathrm{a}^{\mathrm{KO} / \mathrm{WT}}$ RGCs sparsely recombined at E15 (Fig. 7b).

\section{Effects of embryonic, postnatal and adult Brn3a ablation}

The distributions of RGC types in retinas from which one or both copies of Brn3a have been removed at adult stage (P22) in a sparse manner are not significantly different from each other (Fig. $7 \mathrm{~d}$ blue vs. red bars, $p=0.071, \chi^{2}$ statistics, Supplementary Table 1), and only a few instances of abnormal betta cellsBrn3aKO- $\beta$ and large bistratifieds - LB were observed in the Ret ${ }^{\mathrm{CreERT} 2 / \mathrm{WT}}$; Brn3a ${ }^{\mathrm{AP} / \mathrm{KO}}$ dataset. Thus, Brn3a loss of function at the adult age has only minor effects on RGC anatomy. However, perinatal removal of Brn3a results in a significant drop in ON and OFF $\beta$ RGCs (from $27 \%$ to $4.5 \%$ ) and essentially absent ON Spiny RGCs, in addition to the presence of some Brn3aKO- $\beta$ and LB RGCs, resulting in a significant change in RGC type distribution relative to the heterozygote control (Table 2, Fig. 7c, blue vs. red bars, $p=3.9^{*} 10^{-5}, \mathrm{X}^{2}$ statistics, Supplementary Table 1). A large reduction in ON and OFF $\beta$ RGCs (from 24.4\% to $6.5 \%$ ) and relative enrichments in ON-OFF DS RGCs (from 12.7\% to 23\%) and recursive RGCs (from $11.4 \%$ to $21 \%$ ) result in significantly altered RGC distribution in E15 induced Ret ${ }^{\mathrm{CreERT} 2 / \mathrm{WT}}$; Brn3 $\mathrm{a}^{\mathrm{AP} / \mathrm{KO}}$ vs. Ret $^{\mathrm{CreERT} 2 / \mathrm{WT}}$; Brn3a ${ }^{\mathrm{AP} / \mathrm{WT}}$ samples (Table 2, Fig. 7b, red vs. blue bars, $p=6^{*} 10^{-7}, \chi^{2}$ statistics, Supplementary Table 1). These phenotypic changes are in keeps with the previously published depletion of $\mathrm{ON}$ and OFF $\beta$ RGCs and relative enrichment in bistratified RGCs that was previously reported for early embryonic loss of function of Brn3a (either sparse or complete). Thus, Brn3a is critical for specification of ON and OFF $\beta$ and ON Spiny RGCs at both E15 and P0, but is less important for their maintenance. Of note, E15 sparse random recombination in $\operatorname{Ret}^{\mathrm{CrEERT2} / W T}$; $B r n 3 a^{C K O A P / K O}$ retinas results in the specification of

\footnotetext{
(See figure on next page.)

Fig. 10 Dynamic co-expression and cross-regulation of Ret and Brn3a during embryonic and postnatal development. a,b Immunostaining of retina sections from E15 (a) and PO (b) Rax:Cre; Brn3a CKOAP/WT (top row) and Rax:Cre; Brn3a ${ }^{C K O A P / K O}$ (bottom row) mice, using anti-Ret (white), anti- GFRa1 (green) and anti-alkaline phosphatase (anti-AP, red) antibodies, and DAPI nuclear stain. (c,d) Pie-charts and (e,f) box-plots representing proportions

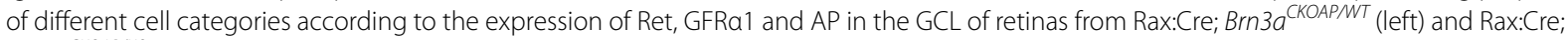
Brn3a $a^{C K O A P / K O}$ (right) animals at E15 (c,e) and PO (d,f). Total number of cells for each category are presented next to the pie-chart markers, and data spread for each category is shown in the boxplots, expressed as percent total DAPI positive cells in the GCL. (g,h) Immunostaining of retina

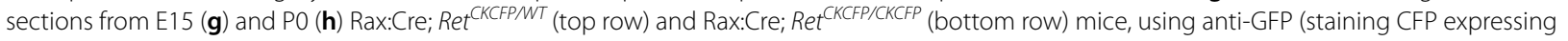
cells, green) together with anti-Brn3a (red), anti-Brn3b (white) antibodies, and DAPI nuclear stain. i,j Pie-charts and (k,l) box-plots representing

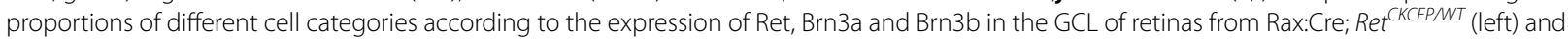

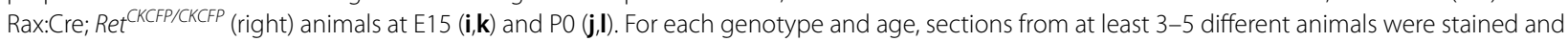
6-13 images were quantified (Supplementary Table 2). Scale bar (h) is $25 \mu \mathrm{m}$. Total number of cells, medians and statistics for pie charts and box plots are indicated in Supplementary Table 2
} 

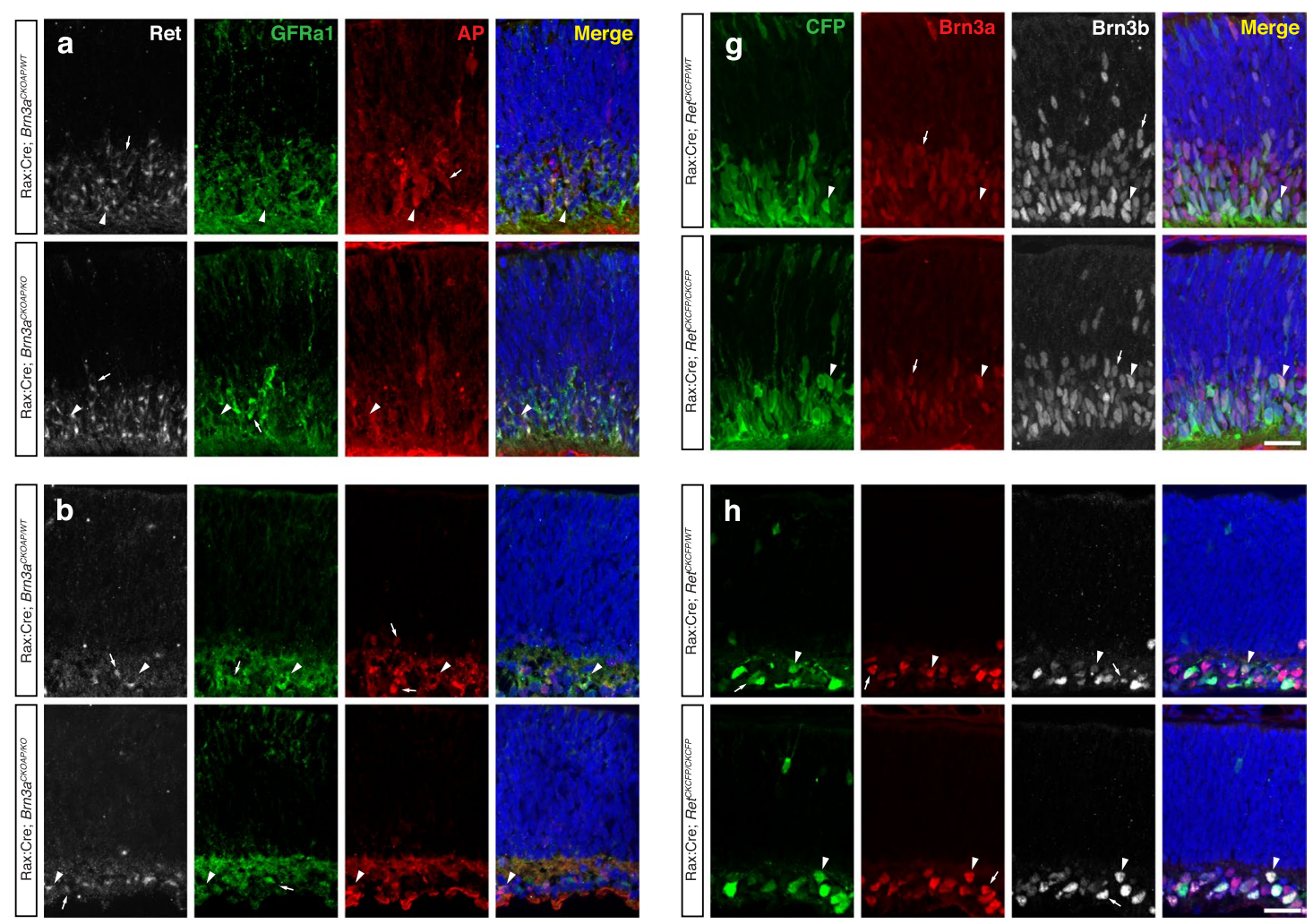

Rax:Cre; Brn3a $a^{\text {CKOAPNT }} \quad$ Rax:Cre; Brn3 $a^{\text {СКOAPKO }}$
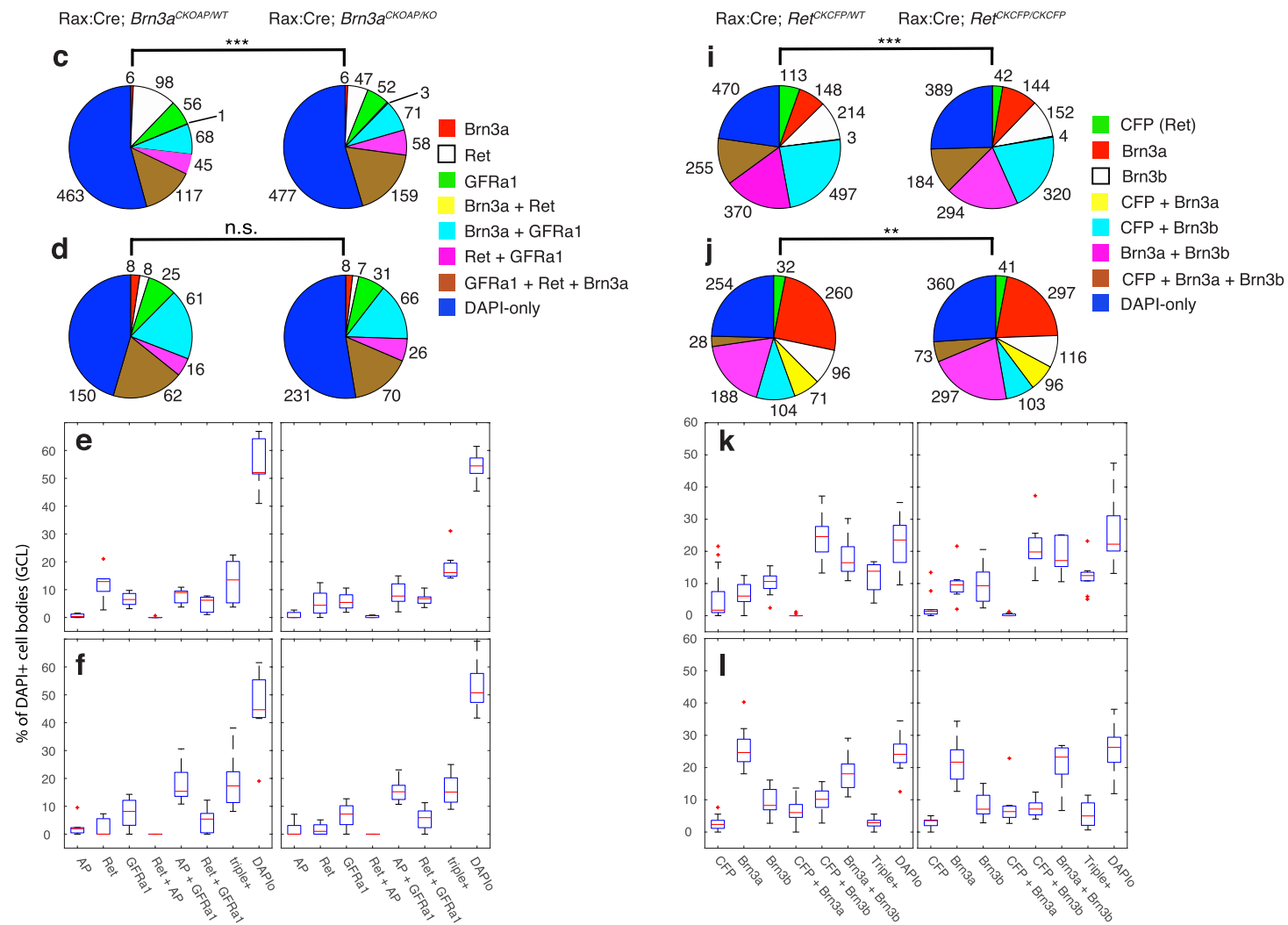

Fig. 10 (See legend on previous page.) 
Table 2 RGC subtype frequencies in different experimental ages and groups (relative to the total number of RGCs in an experimental group)

\begin{tabular}{|c|c|c|c|c|c|c|c|c|}
\hline RGC subtype & ROSA Brn3aHET & $\begin{array}{l}\text { ROSA } \\
\text { Brn3aWT }\end{array}$ & $\begin{array}{l}\text { E15 } \\
\text { Brn3aHET }\end{array}$ & $\begin{array}{l}\text { E15 } \\
\text { Brn3aKo }\end{array}$ & $\begin{array}{l}\text { PO } \\
\text { Brn3aHET }\end{array}$ & $\begin{array}{l}\text { P0 } \\
\text { Brn3aKo }\end{array}$ & $\begin{array}{l}\text { P22 } \\
\text { Brn3aHET }\end{array}$ & $\begin{array}{l}\text { P22 } \\
\text { Brn3aKo }\end{array}$ \\
\hline ON alpha & 8.9 & 6.5 & 7.4 & 9.5 & none & none & none & none \\
\hline M5 & 17.2 & 19.6 & 24.1 & 22.8 & none & none & none & none \\
\hline ON spiny & 1.2 & 0.7 & 2.8 & 0.9 & 2.2 & none & 4.7 & 8.3 \\
\hline ON and OFF $\beta$ & 12.4 & 13.8 & 24.4 & 6.5 & 27 & 4.5 & 27 & 17.2 \\
\hline OFF transient & none & none & 0.6 & none & 3.4 & 9 & 2.7 & 2.8 \\
\hline OFF sustained & none & none & 0.6 & 0.9 & 1.1 & none & none & none \\
\hline M1 & none & 1.4 & none & none & none & none & none & none \\
\hline Brn3aKO $\beta$ & none & none & none & none & none & 4.5 & none & 2.8 \\
\hline Mono Total & 39.6 & 42 & 59.9 & 40.5 & 34.8 & 18 & 35.8 & 31.7 \\
\hline ON-OFF DS & 37.3 & 34.8 & 12.7 & 23.3 & 19.1 & 39.3 & 31.8 & 35.8 \\
\hline SB & 15.4 & 12.3 & none & none & 28.1 & 21.3 & 22.3 & 20 \\
\hline Recursive & 1.2 & 5.1 & 11.4 & 21.1 & 18 & 14.6 & 9.5 & 7.6 \\
\hline Large Bistratified & 2.4 & none & none & none & none & 3.4 & 0.7 & 4.8 \\
\hline ONDS & 3.6 & 5.8 & 4 & 3.4 & none & none & none & none \\
\hline Abnormal type 1 & none & none & 7.7 & 8.2 & none & none & none & none \\
\hline Abnormal type 2 & none & none & 4.3 & 3.4 & none & none & none & none \\
\hline Brn3aKO Bistr & none & none & none & none & none & 3.4 & none & none \\
\hline Bi Total & 60.4 & 58 & 40.1 & 59.5 & 65.2 & 82 & 64.2 & 68.3 \\
\hline
\end{tabular}

similar numbers of ON-DS, M5, ONaS, AT1 and AT2 RGCs as are seen in the E15 $\operatorname{Ret}^{\mathrm{CreERT2} / W T} ; \mathrm{Brn} 3 a^{\mathrm{CK}-}$ $O A P / W T$ controls (Fig. 7b, red vs blue bars, Table 2), while SB RGCs are missing from both samples. These E15 specific changes point to the possibility that the random sparse Brn3a copy number deficit induced in Ret $^{\text {CreERT2/WT }}$ RGCs relative to the surrounding retina (Brn3a ${ }^{\mathrm{KO} / \mathrm{KO}} \mathrm{RGCs}$ vs Brn3a ${ }^{\mathrm{KO} / W \mathrm{~T}}$ retina OR Brn3a $\mathrm{a}^{\mathrm{KO} /}$ ${ }^{\mathrm{WT}}$ RGCs vs Brn3aWT/WT retina) may be responsible for this subset of phenotypes.

\section{Regulatory crosstalk between Ret and Brn3a}

The distinct effects of global versus sparse random manipulation of Brn3a dosage on RGC type distribution suggest a genetic interaction between Ret and Brn3a and prompted us to ask whether they regulate each other at transcriptional level. We therefore compared co-expression of Ret protein and the Alkaline phosphatase (AP) reporter in full-retina Brn3a-heterozygote (Rax:Cre; Brn3a $a^{C K O A P / W T}$ ) and full-retina Brn3a-knockout (Rax:Cre; Brn $3 a^{C K O A P / K O}$, Fig. 8 a-d) sections. The distribution of $\mathrm{Ret}^{+}, \mathrm{AP}^{+}$and $\mathrm{Ret}^{+} \mathrm{AP}^{+}$(double-positive) cells is similar regardless of Brn3a dosage, with a modest (statistically insignificant) decrease of doublepositive cells in Rax:Cre; Brn $3 a^{C K O A P / K O}$ (Fig. 8 b, c, Supplementary Table 2). Nevertheless, the overall shift from $\mathrm{AP}^{+}$Ret $^{+}$double positive cells to single $\mathrm{AP}^{+}$or $\mathrm{Ret}^{+}$ positive cells in $\mathrm{Brn} 3 \mathrm{a}^{\mathrm{KO}}$ retinas is statistically significant ( $\chi^{2}$ ChiStat $=10.81, p=0.013$ ) potentially suggesting that Brn3a controls Ret in a subset of RGC types.

We then asked whether Ret signaling can regulate Brn3a or Brn3b transcription. Co-expression of the conditional knock-in reporter CFP with either Brn3a or Brn3b was compared in full-retina Ret-heterozygotes (Rax:Cre; $\operatorname{Ret}^{C K C F P / W T}$ ) and full-retina Ret-knockouts (Rax:Cre Ret ${ }^{C K C F P / C K C F P}$, Fig. $8 \mathrm{e}-\mathrm{h}$ ). In this line, the CFP reporter is expressed from the Ret locus after the removal of the Ret cDNA by Cre recombination [100]. We observed RGCs expressing Ret either alone or in combination with Brn3a, Brn3b or both. The distribution of single, double and triple labelled cells is conserved in the two backgrounds (Fig. 8 f, g, Supplementary Table 2), suggesting that Ret is not required for Brn3a or Brn3b expression in RGCs. Thus it is unlikely that the genetic interaction observed in sparsely recombined RGCs is mediated by reciprocal transcriptional control of Ret and Brn3a.

\section{Brn3a modulates GDNF ligand signaling to RGCs by regulating GFRa Ret co-receptors}

We next asked whether GFR $\alpha$ Ret co-receptors are expressed in Brn3a ${ }^{+}$RGCs and/or regulated by Brn3a. Data from a deep sequencing analysis screen of Brn3a transcriptional targets expressed in RGCs [78, 92] 
shows that Ret and GFRo's are expressed in RGCs at E15 and P3 (Supplementary Fig. 1). While Ret expression levels are relatively high (around 20 FPKM), the co-receptors are expressed at much lower levels. The major GFR $\alpha 1$ transcript is mostly expressed in Brn3b ${ }^{\mathrm{AP}}$ RGCs at both E15 and P3 (around 5 FPKM), and somewhat less in $\mathrm{Brn} 3 \mathrm{a}^{\mathrm{AP} / \mathrm{WT}} \mathrm{RGCs}$ at P3 (1.2 FPKM), and its expression is nearly doubled in Brn3a ${ }^{A P / K O}$ RGCs, suggesting negative regulation by Brn3a. GFR $\alpha 2$ is homogeneously expressed across all Brn3 $^{\mathrm{AP}}$ RGCs at both E15 and P3 (about 4-6 FPKM), but is not regulated by Brn3a. GFR $\alpha 3$ is and GFR $\alpha 4$ are expressed at less than 1 FPKM in P3 Brn $3^{\mathrm{AP}}$ RGCs and do not appear regulated by either Brn3 transcription factor (Sajgo 2017 and Supplementary Fig. 1). Since adult GFR $\alpha$ expression had been previously reported in RGCs [15], we stained adult Rax:Cre; Brn3aCKOAP/ $W_{T}$ and Rax:Cre; Brn3a ${ }^{C K O A P / K O}$ retina sections with anti-GFR $\alpha 1$, GFR $\alpha 2$ and GFR $\alpha 3$ antibodies (Fig. 9, Supplementary Table 2). When comparing $B r n 3 a^{A P /}$ $W T$ to $B r n 3 a^{A P / K O}$ retinas (Fig. 9, g-h, i-j, k-l Supplementary Table 2), loss of Brn3a results in significant increases in GFR $\alpha 1^{+}-\mathrm{GFR} \alpha 3^{+}$GCL cells $(18.8$ to $25,25.8$ to 33.33 and 38.2 to $54 \% \mathrm{DAPI}^{+}$cells in GCL, respectively). Consistent with previous reports, Brn3a ${ }^{A P}$ RGCs numbers are reduced as a result of Brn3a ablation (26 to $18.8,20.18$ to 9 and 4.35 to $2.4 \%$ $\mathrm{DAPI}^{+}$cells in GCL, respectively), however GFR $\alpha 1^{+}$ $\mathrm{Brn} 3 \mathrm{a}^{\mathrm{AP}}$ and $\mathrm{GFR} \alpha 2^{+} \mathrm{Brn} \mathrm{a}^{\mathrm{AP}}$ double positive ratios are not significantly affected $\left(\mathrm{GFR} \alpha 1^{+} \mathrm{Brn}^{\mathrm{A}} \mathrm{a}^{\mathrm{AP}}: 7.5 \mathrm{vs}\right.$. 11.7 and GFR $\alpha 2^{+}$Brn3a $^{\mathrm{AP}^{\mathrm{P}}}: 12.7$ vs $11.3 \% \mathrm{DAPI}^{+}$cells in GCL). There is also a sizable but statistically insignificant decrease in GFR $\alpha 3^{+}$Brn3a ${ }^{A P}$ RGCs. Overall, the partial overlap between all three GFR $\alpha$ receptors and Brn3a ${ }^{\mathrm{AP}}$ is significantly altered by Brn3a ablation (Fig. 9 g, i, k), resulting in a shift away from Brn3a ${ }^{A P}$ and towards GFR $\alpha$ expression. This shift could be caused by a fate change of Brn3a ${ }^{\mathrm{AP}}$ RGCs towards $\mathrm{GFR}^{+} \mathrm{RGCs}$ (or displaced amacrine cells) in $B r n 3 a^{A P \prime}$ ${ }^{K O}$ retinas, since the ratios of GFR $\alpha^{+} \mathrm{Brn} 3 \mathrm{a}^{\mathrm{AP}} \mathrm{RGCs}$ are not significantly changed. We note that the cumulative number of positive cells for GFR $\alpha 3^{+}$and Brn $3 \mathrm{a}^{\mathrm{AP}}$ greatly exceeds $40-50 \%$ of the DAPI positive cells in the GCL, signaling that a good number of GFR $\alpha 3^{+}$ cells are amacrine neurons, as Brn3a labels some $90 \%$ of all RGCs in the adult. Interestingly, the antibody staining for both GFR $\alpha 1^{+}$and GFR $\alpha 2^{+}$reveals increased dendritic arbor labelling in close proximity to the GCL, suggesting that most GFR $\alpha 1^{+}$and GFR $\alpha 2^{+}$RGCs are laminating in the sublamina which

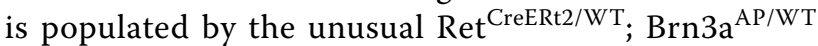
or Ret ${ }^{\mathrm{CreER} 2 / \mathrm{WT}}$; Brn3a ${ }^{\mathrm{AP} / \mathrm{KO}} \mathrm{RGC}$ types induced at E15 (ONaS, M5, AT1, AT2).
Ret and its GFRa co-receptors are expressed in Brn3a ${ }^{+} \mathrm{RGCs}$ during development

RGC cell type distribution appears to be affected by Ret and Brn3a gene dosage manipulations at embryonic and early postnatal ages, but not in the adult. We therefore investigated the co-expression of Ret and Brn3a at E15 and P0 (Fig. 10), using the same conditional knock-in strategies employed in Fig. 8 and 9. At both E15 and P0, essentially all Brn3a ${ }^{+}$RGCs in Rax:Cre; Brn3a $a^{C K O A P / W T}$ retinas fall in either the Brn3a ${ }^{\mathrm{AP}} \operatorname{Ret}^{+} \mathrm{GFR} \alpha 1^{+}$(13.5 and $17.3 \%$ of $\mathrm{DAPI}^{+} \mathrm{GCL}$ cells) or $\mathrm{Brn} \mathrm{a}^{\mathrm{AP}} \mathrm{GFR} \alpha 1^{+}$(8.9 and $15.3 \%$ of $\mathrm{DAPI}^{+}$ GCL cells), with essentially no Brn3a ${ }^{\mathrm{AP}}$ or Brn $3 \mathrm{a}^{\mathrm{AP}} \mathrm{Ret}^{+}$ RGCs present (Fig. 10a-f, Supplementary Table 2). Removing both copies of Brn3a (in Rax:Cre; Brn3a $a^{C K}$ $O A P / K O$ retinas), does not produce statistically significant alterations of individual single, double or triple stained populations in either E15 or P0 retinas (Fig. 10e, f). In E15 retinas, a modest increase of Brn3a ${ }^{\mathrm{AP}} \operatorname{Ret}^{+} \mathrm{GFR} \alpha 1^{+}$cells and decrease of Ret $^{+}$cells results in a statistically shifted overall cell population distribution, which is "corrected" by P0. Thus, Brn3a has a large overlap of expression with Ret and GFR $\alpha 1^{+}$ in both embryonic and early postnatal development, but does not play a major role in their transcriptional regulation, at least at population level. Both GFR $\alpha 2^{+}$ and $\mathrm{GFR} \alpha 3^{+}$are expressed in Brn3a ${ }^{\mathrm{AP}}$ RGCs at E15 (Supplementary Fig. 2) and P0 (data not shown), mostly in conjunction with Ret (as Brn3a ${ }^{\mathrm{AP}} \operatorname{Ret}^{+} \mathrm{GFR} \alpha 2^{+}$and $\mathrm{Brn} 3 \mathrm{a}^{\mathrm{AP}} \operatorname{Ret}^{+} \mathrm{GFR} \alpha 3^{+}$triple positive cells).

When staining for Brn3a and Brn3b in E15 and P0 whole retina Ret heterozygotes (Rax:Cre; Ret ${ }^{C K C F P / W T}$, Fig. 10g-l, Supplementary Table 2), nearly all possible subpopulations of single double and triple positive cells can be observed. However, as previously reported in many studies, E15 retinas contain much larger relative numbers of $\mathrm{Brn} \mathrm{b}^{+}$RGCs (either $\mathrm{Brn} 3 \mathrm{~b}^{+}$,

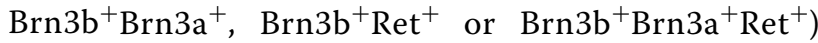
than $\mathrm{P} 0$ retinas $(64.5 \%$ at $\mathrm{E} 15$ vs. $40 \%$ at $\mathrm{P} 0$, overall

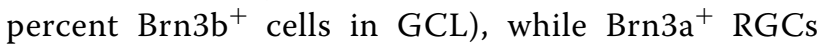
increase in numbers at $\mathrm{P} 0$ relative to $\mathrm{E} 15$ (37.5\% at $\mathrm{E} 15$ vs. $53 \%$ at $\mathrm{P0}$, overall percent ${\mathrm{Brn} 3 \mathrm{a}^{+}}^{+}$cells in GCL). Interestingly co-expression of Brn3a and Ret at E15 is seen only as triple positive RGCs $\left(\mathrm{Brn} 3 \mathrm{~b}^{+} \mathrm{Brn} \mathrm{a}^{+} \mathrm{Ret}^{+}\right.$, $13.8 \%$ of DAPI $=$ cells in GCL), and Brn3a ${ }^{+}$Ret $^{+}$ RGCs are essentially non-existent (Fig. 10g, i, k). At P0, Brn3a ${ }^{+}$Ret $^{+}$RGCs make up $6 \%$ of the GCL, while $\mathrm{Brn} 3 \mathrm{~b}^{+} \mathrm{Brn} 3 \mathrm{a}^{+} \mathrm{Ret}^{+}$RGCs are diminishing to $2.9 \%$ (Fig. 10h, $\mathrm{j}, \mathrm{l}$ ), beginning to resemble the adult distribution (compare to Fig. 8e-f). Like in the adult, removing both copies of Ret (Rax:Cre; $\operatorname{Ret}^{\text {CKCFP/CKCFP }}$ ) results in minor (statistically not significant) shifts of several populations relative to the controls, (Fig. 10k, 
1) but the overall cell type distributions are significantly shifted at both E15 and P0 (Fig. 10i, j).

In summary, Ret and Brn3a exhibit significant expression overlap at both E15 and P0, but no dramatic transcriptional regulatory effects in either direction can be documented.

\section{Expression of some downstream Ret signaling components is affected by Brn3a loss of function in RGCs}

Since transcriptional effects of Brn3a loss on Ret or its coreceptors is modest, we sought to identify further potential targets of Brn3a that could explain its genetic interaction with the Ret pathway. Several signaling cascades (MAPK, SRC-GRB, PI3K, Akt, NFkB and apoptotic pathways), are known to play a role in neurotrophic signaling downstream of the Ret receptor [2, 19, 26, 58]. We determined the representation of members of these signaling cascades amongst $\mathrm{Brn}_{3} \mathrm{a}^{+} \mathrm{RGCs}$ and Brn3a target genes [78, 92], and identified a subset of genes that are enriched in $\mathrm{Brn}_{3} \mathrm{a}^{+}$and/or $\mathrm{Brn} 3 \mathrm{~b}^{+}$RGCs relative to the retina (cluster branches highlighted in red in Supplementary Fig. 3a, and isolated in 3b). Of these, 12 are also expressed beginning with E15 in RGCs, and most are under transcriptional control of Brn3b (compare vertical branches 3 and 4 of the hierarchical clustering map in Fig. 3a). One isoform of Rapgef1 and two isoforms of Camk2d were upregulated and one isoform of Prkcz downregulated in Brn3a ${ }^{\mathrm{AP} / \mathrm{KO}} \mathrm{RGCs}$ when compared to Brn3a ${ }^{\mathrm{AP} / W \mathrm{~T}}$ RGCs (Supplementary Fig. 3c). These could represent potential targets for the mechanisms by which Brn3a interferes in Ret downstream signaling.

\section{Modest reduction of TrkA and TrkC expression in $\mathrm{Brn} 3 \mathrm{a}^{\mathrm{AP} /}$ ${ }^{\mathrm{KO}} \mathrm{RGCs}$}

Brn3a regulation of Trk neurotrophin receptors is believed to play a major role in cell type specification of projection sensory neurons of the somatosensory (DRG and TGG), auditory and vestibular pathways, and the GDNF-GFR $\alpha$ and NGF - Trk neurotrophic signaling axes interact in cell type specification [37, 42, 74]. We therefore asked whether Trk receptor expression in RGCs is regulated by Brn3a. Our RNAseq data predicted that all three Trk receptors (TrkA/Ntrk1, TrkB/ Ntrk2 and TrkC/Ntrk3) and p75/NGFr are expressed in RGCs at E15 and P3, and that Brn3a is positively regulating TrkA and TrkC and negatively regulating TrkB $([78,92]$ and Supplementary Fig. 4), while TrkB expression in adult mouse RGCs had been previously reported [18]. Using antibody staining in the adult retina, we find that $\operatorname{TrkB}$ is expressed in a large fraction of GCL cells, and a majority of Brn3a ${ }^{\mathrm{AP}} \mathrm{RGCs}$ in both $B r n 3 a^{A P /}$ ${ }^{W T}$ or $B r n 3 a^{A P / K O}$ retinas (Supplementary Fig. $5 \mathrm{e}-\mathrm{h}$,
Supplementary Table 2). In contrast, TrkA is partially co-expressed with Brn3a in a small fraction of RGCs, and the fraction of TrkA ${ }^{+}$Brn3a ${ }^{A P}$ RGCs is somewhat reduced in $B r n 3 a^{A P / K O}$ retinas (from 6.8 to $1.8 \% \mathrm{DAPI}^{+}$ cells in GCL, Supplementary Fig. 5 a - d, Supplementary Table 2). A majority of Brn3a ${ }^{\mathrm{AP}}$ RGCs expressed $\operatorname{TrkC}$, and the number of $\operatorname{TrkC}^{+} \mathrm{Brn}_{3} \mathrm{a}^{\mathrm{AP}}$ RGCs was mildly reduced by Brn3a ablation (from 34.6 to $28.5 \%$ DAPI $^{+}$cells in GCL, Supplementary Fig. 5 i-l, Supplementary Table 2). While none of the individual cell population changes were statistically significant using the KS2 test, TrkA and TrkC vs. Brn3a ${ }^{A P}$ populations were significantly shifted in $B r n 3 a^{A P / W T}$ vs $B r n 3 a^{A P / K O}$ retinas, as judged by the Chi-Square distribution test.

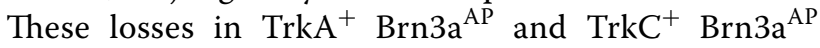
RGCs may be due either to direct transcriptional regulation of the two Trk receptors by Brn3a or by the loss of specific Brn3a ${ }^{A P}$ RGC subpopulations due to Brn3a ablation. It is worth pointing out that TrkA dendritic arbors were distributed in three sharp lamina across the IPL, with the most intense one being apposed against the GCL, as seen for GFR $\alpha 1^{+}$and GFR $\alpha 2^{+}$, while TrkC exhibited lamination in the OFF sublaminae of the IPL. All three Trk receptors are expressed in the GCL and the proximal INL, suggesting expression in Amacrine cells in addition to RGCs.

\section{Discussion}

Our results show that altering the dosage of Brn3a in a sparse mosaic fashion early (E15) in the development of Ret heterozygote (Ret ${ }^{\mathrm{CreER} 2 / \mathrm{WT}}$ ) RGCs can change the cell type distribution and/or morphologies of heterozygote (Brn3a ${ }^{\mathrm{AP} / \mathrm{WT}}$ ) and knockout $\left(\mathrm{Brn} 3 \mathrm{a}^{\mathrm{AP} / \mathrm{KO}}\right)$ RGCs. RGCs are not affected when Brn3a is removed in the adult, and mildly affected by Brn3a removal immediately after birth. E15 or P0 removal of both copies of Brn3a results in dramatic losses in ON and OFF $\beta$ and ON spiny RGCs, suggesting a significant role for Brn3a in the development of these cell populations. Germline

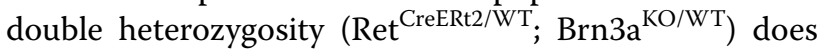
not phenocopy the results obtained with the mosaic heterozygotes and results in normal RGC type specification. Immunohistochemical evidence collected in whole retina knockouts of either Ret or Brn3a shows a modest transcriptional control of Ret by Brn3a while neither Brn3a nor Brn3b are affected by complete retinal loss of Ret. However full retinal loss of Brn3a results in modest, but significant shifts in expression of Ret co-receptors GFR $\alpha 1-3$ in the GCL and mildly reduces neurotrophin receptors TrkA and TrkC expression in Brn3a ${ }^{\mathrm{AP}}$ RGCs. Thus, the simplest explanation of our data is that Ret and Brn3a participate in converging developmental pathways 
that control RGC type specification at the early stages of postmitotic development, and potentially use a competitive mechanism based on gene dosage. The range of RGC types reported in this study was largely similar with previous reports, and equivalencies to previously reported anatomies, including a serial EM dataset (EyeWire museum) [12] are provided in Table 1.

\section{Brn3a requirement in early versus late $\mathrm{RGC}$ development}

$\mathrm{Brn} 3 \mathrm{a}$ is required for the development of ON and OFF $\beta$ RGCs and some bistratified RGC types, and Brn3a $\mathrm{KO}$ animals have a net RGC loss of about 30\% [5, 7, 85, 93]. Ablating either Brn3a, Brn3b or both in adult mice does not affect RGC numbers up to six months post ablation [45]. We now show that adult ablation of Brn3a does not significantly alter the cell type distribution

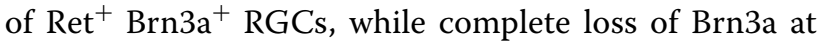
P0 and E15 produces a significant overall shift in RGC type distribution between $\operatorname{Ret}^{\mathrm{CreERt} 2 / \mathrm{WT}} \mathrm{Brn} 3 \mathrm{a}^{\mathrm{AP} / \mathrm{WT}}$ and Ret $^{\text {CreERt2/WT }}$ Brn3a ${ }^{A P / K O}$ RGCs, largely based on the dramatic loss of ON and OFF $\beta$ RGCs (ratios in Het vs. KO are $27 \%$ vs. $17.2 \%$ at $\mathrm{P} 22,27 \%$ vs. $4.5 \%$ at $\mathrm{P} 0$ and $24.4 \%$ vs. $6.5 \%$ at E15). Thus, Brn3a is required for the development of these cells but not for maintenance in the adult. In P0 and P22 induced Brn3a ${ }^{\mathrm{AP} / \mathrm{KO}}$ RGCs we also detected an unusual dendritic arbor morphology reminiscent of ON $\beta$ RGCs, but distinguishable by larger areas and less dense dendritic coverage potentially representing abnormal ON betta RGCs resulting from relatively late loss of Brn3a. ON spiny RGCs are also selectively reduced in E15 and P0 but not adult inductions, suggesting an early dependency on Brn3a. Furthermore, two types of bistratified RGCs (LB and Brn3aKO - bistratifieds) are observed specifically in P0 and P22 induced Brn3a ${ }^{\mathrm{AP} / \mathrm{KO}}$ RGCs. LB (Large Bistratifed) RGCs have been previously seen in WT circumstances [7, 85, 93], especially in Brn3b ${ }^{+}$RGCs, and therefore could represent another shift of cell type specificity, induced only in Ret $^{\text {CreERt2/WT }}$ Brn3a ${ }^{A P / K O}$ RGCs. However, the simplified arbors of Brn3aKO-bistratifieds point to a developmental defect as a result of Brn3a loss, and is independent of Ret, since they were observed in Brn3a ablations using other Cre drivers [5, 7].

\section{Ret and Brn3a: Genetic interaction versus developmental dynamic shift of expression}

Is it possible that the shift in RGC morphologies seen upon embryonic recombination reflects the dynamic expression pattern of Ret or Brn3a in RGCs? The dynamic expression pattern of Ret was shown to be important for specification of subpopulations of DRG neurons [67, 68] and we have documented the dynamic expression of Ret in RGCs, Horizontal cells and Amacrines during embryonic and postnatal retinal development. However, the distribution of RGC types in $\operatorname{Ret}^{\mathrm{CreERt2} / W T}$; ROSA26 ${ }^{A P /}$ $W T$ mice seems to be relatively stable from E15 through P14 to adult, (data in Fig. 6 in this study and Figs. 6 and 7 in [85]), arguing that the expression profile of Ret ${ }^{\text {CreERt2 is }}$ relatively unchanged during RGC development. In addition, for all experiments involving the $B r n 3 a^{C K O A P / W T}$ allele, the cell type distribution is collected and analyzed in adult mice regardless of induction time, using $\mathrm{AP}$ expressed under the control of the Brn3a locus (Brn3a ${ }^{\mathrm{AP}}$ ), thus reflecting only the adult expression profile of Brn3a.

The RGC morphologies observed when recombination is induced in adult $R e t^{\mathrm{CreERt} / W T} ; \mathrm{Brn} 3 a^{C K O A P / W T}$ mice are in agreement with our previously published data regarding Brn3a expression in various RGC types. In previous studies, recombination was achieved using either transgenic elements (Pax6 $\alpha$ :Cre or Rax:Cre) that are activated at E9.5 to 10.5, or sparse random recombination induced using alleles with no known biological effects or preferential expression patterns, under the control of the ROSA26 locus or CAG promoter, induced at a variety of ages, from E8 to adult. The repertoire of RGC types positive for Brn3a revealed by sparse labelling using general promoters (ROSA26, Pax6 $\alpha$ :Cre) shows a dendrite lamination pattern typically excluding the innermost $20-30 \%$ of the IPL. This pattern is confirmed by immunofluorescent staining in sections where the totality of Brn3 $\mathrm{a}^{\mathrm{AP}}$ RGC dendrites is revealed using whole retina Cre drivers such as Pax6a:Cre and Rax:Cre $([5,78,93]$ and Fig. $8 \mathrm{a}$ in this study). It is therefore likely that P0 and adult-induced Ret $^{\text {CreERt2/WT; }}$ Brn3a ${ }^{A P / W T}$ RGCs accurately reflect the expression overlap of Ret and Brn3a in RGCs.

Overall, five cell types are unique to the E15 induced Ret $^{\mathrm{CreER} 2 / \mathrm{WT}}$; Brn3a ${ }^{\mathrm{AP} / \mathrm{WT}}$ RGCs population as contrasted to P0/adult induced RGCs: ONaS, M5, ON-DS, AT1 and AT2 (Fig. 7b). They make up a sizeable fraction (47\%) of all E15 induced RGCs. Of these, only ON-DS cells are known to be Brn3a positive in the adult and are also present in the general E15 Ret RGC expression profile (Ret ${ }^{C r e R t 2}$; Rosa26 ${ }^{i A P}$ data, Fig. 7a), and thus could be explained by a shift of expression of Ret between E15 and P0/adult. The other four cell types have not been previously reported to be Brn3a positive. Furthermore, while $\mathrm{ON \alpha S}, \mathrm{M} 5$, and ON-DS cells are present in E15 and adult induced $R e t^{\text {CreRt2 }}$; Rosa $26^{i A P}$ mice, AT1 and AT2 are completely missing from these data sets. Since $\mathrm{ON \alpha S}$ and M5 can be reliably matched to $\operatorname{Ret}^{+}$RGC types (compare top of Fig. 7a and b), their appearance in E15 induced RetBrn3a double heterozygotes could be interpreted as an induction of Brn3a expression in these cell types, or a cell type shift caused by the genetic interaction between Ret and Brn3a. In contrast AT2 and AT1 could be derived from a faulty cell type specification decision, separating 
them from the normal $\operatorname{Ret}^{+} \mathrm{Brn} 3 \mathrm{a}^{+}$fate and resulted from the combined heterozygote loss of Brn3a and Ret. AT2 is tentatively matched morphologically to cell type 85 in the EyeWire museum, and we described one instance in a general RGC description in 2004 [8], and AT1 does appear to be a novel morphology. It is possible that AT1 and AT2 morphologies result from developmental changes in SB cells, which are absent from E15 specified Ret $^{\text {CreERt2 }}$ Brn3a ${ }^{\mathrm{AP}}$ RGCs, but are present in large numbers in $\mathrm{E} 15$ induced Ret ${ }^{\text {CreRt2 }}$; Rosa26 ${ }^{\mathrm{iAP}}$ RGCs (compare bottom of Fig. 7a and b). We conclude that labelling of ONo, M5, AT1 and AT2 RGCs in Ret ${ }^{\mathrm{CreER} 2 / \mathrm{WT}}$; Brn3a ${ }^{\mathrm{AP} /}$ ${ }^{\text {WT }}$ RGCs induced at E15 but not at P0 or P22 is a result of genetic interactions between Ret and Brn3a, rather than a reflection of a normal change in expression patterns of Ret, Brn3a or both throughout development. Presumably, cell type specificity and/or Ret and Brn3a expression are determined by $\mathrm{P} 0$, such that after a loss of one or even both alleles of Brn3a in conjunction with the heterozygous state of Ret, the distribution of $\operatorname{Ret}^{+}{\mathrm{Brn} 3 \mathrm{a}^{+}}^{+}$ RGC types is relatively unaffected.

\section{Sparse versus Complete double heterozygosity}

In Ret $t^{C r e E R t 2 / W T} ; \quad B r n 3 a^{C K O A P / W T}$ and $\operatorname{Ret}^{\mathrm{CreERt} 2 / W T}$; $\mathrm{Brn} 3 \mathrm{a}^{C K O A P / K O}$ mice, as sparse recombination is induced at either E15, P0 or adult, labelled RGCs lose one Brn3a allele in comparison to the surrounding tissue $\left(\mathrm{Brn} 3 \mathrm{a}^{\mathrm{AP} /}\right.$ ${ }^{\mathrm{WT}}=$ "Het" RGC in a Brn3a ${ }^{\mathrm{CKOAP} / \mathrm{WT}}=$ "WT" territory, or $\mathrm{Brn} 3 \mathrm{a}^{\mathrm{AP} / \mathrm{KO}}=$ "KO" RGC in a Brn3a ${ }^{\mathrm{CKOAP} / \mathrm{KO}}=$ "Het" territory, see Fig. 1). If, as argued above, E15 induced Ret $^{\mathrm{CreERt} 2 / \mathrm{WT}}$; Brn3a ${ }^{\mathrm{AP} / \mathrm{WT}}$ RGCs reveal a significant cell type distribution shift from the expected $\operatorname{Ret}^{+} \mathrm{Brn} \mathrm{a}^{+}$ fate, this would imply that the $\operatorname{Re} t^{K O / W T} ; \operatorname{Brn} 3 a^{K O / W T}$ double heterozygote state is sufficient to alter developmental choices in RGCs. We therefore compared RGCs from Ret ${ }^{\mathrm{CreERt} 2 / W T}$; Brn3a ${ }^{K O / W T}$; Rosa26 ${ }^{i A P / W T}$ and RetCreERt2/WT; Brn3a $a^{W T / W T}$; Rosa26 $6^{i A P / W T}$ adult mice, in which recombination had been induced at E15. In this case, labelled RGCs are either double heterozygotes (Ret ${ }^{\mathrm{CreER} 2 / \mathrm{WT}} ; \mathrm{Brn} 3 \mathrm{a}^{\mathrm{KO} / \mathrm{WT}}$ ) or single Ret heterozygotes (Ret ${ }^{\mathrm{CreER} 2 / \mathrm{WT}} ;$ Brn3a ${ }^{\mathrm{WT} / \mathrm{WT}}$ ), respectively, and carry the same number of Ret and Brn3a alleles as the surrounding retinal tissue from conception into adulthood. Interestingly, we found that all RGC morphologies are consistent with the previously reported Ret expression domain, regardless of Brn3a dosage. Moreover, Ret ${ }^{\mathrm{CreER} 2 / \mathrm{WT}}$; Brn3a ${ }^{\mathrm{AP} / \mathrm{KO}}$ RGCs labelled by P0 or P22 induction are effectively germline double heterozygotes before recombination, from conception to P0 or P22 respectively, since they carry one wild type allele (unrecombined Brn3a ${ }^{\mathrm{CKOAP}}$ ), and one constitutive Brn3a $\mathrm{KO}$ allele $\left(\mathrm{Brn} 3 \mathrm{a}^{\mathrm{KO}}\right)$ up to the time of recombination. These populations resemble the expected $\operatorname{Ret}^{+}{\mathrm{Brn} 3 \mathrm{a}^{+}}^{+}$ expression domain (with the mentioned exceptions of ON and OFF $\beta$ and ON Spiny RGCs), but are quite distinct from the E15 induced Ret ${ }^{\mathrm{CreERt} 2 / \mathrm{WT}}$; Brn3a ${ }^{\mathrm{AP}}$ RGCs, regardless of Brn3a dosage. Combined, these observations strongly suggest that only early sparse but not complete $\operatorname{Ret} t^{K O / W T}$; Brn $3 a^{K O / W T}$ combined heterozygosity can induce significant shifts in cell type distribution or morphological changes in RGCs. Potentially, Ret signaling in combination with information provided through Brn3a transcriptional control acts as a competitive factor in cell type specification of RGCs. Sparse double heterozygotes receive altered signals compared to the surrounding tissue, and therefore adopt novel cell fates or acquire altered morphologies. In the germline double or single heterozygotes, labelled RGCs and surrounding tissue have the same dosage of Ret and Brn3a, resulting in unaltered RGC type specification decisions. A similar phenomenon is observed in Purkinje neurons, which exhibit defects in dendrite morphogenesis in the presence of sparse but not germline knockout of the TrkC neurotrophin receptor [57].

\section{What are the molecular mechanisms of cross-talk between Ret and Brn3a?}

A previous characterization of Ret function in the retina [15], and our own analysis (Fig. 8e-h) do not suggest a role for Ret in RGC survival. Conversely, in previous work $[5,7,93]$, we had shown that the loss of ON/ OFF betta RGCs in $B r n 3 a^{A P / K O}$ retinas is mirrored by a $20-30 \%$ reduction in total RGC numbers (reproduced in this study in Fig. 8a-d), and it is as of yet unclear whether that is a result of increased apoptosis or cell fate shifts. However it should be emphasized that both Ret and Brn3a are expressed in postmitotic neurons. Thus any developmental shifts we see in our system would be operating on the early stages of RGC type differentiation, after the last cell cycle. In the somatosensory system there is a well-established role for neurotrophic signaling in neuronal specification, survival, differentiation, and neurite growth and branching $[2,19,36,37,42,43,74]$. TrkA/B/C as well as Ret and its GFR $\alpha$ co-receptors are necessary for the specification of classes of nociceptors, mechanoreceptors and proprioceptors $[39,67,68]$. Transcriptional regulation of neurotrophic receptors plays a major role in cell type specification of other projection sensory neurons $[21,22,60]$. Brn3a and its family members are important regulators of development and specification of projection neurons in the Trigeminal Ganglion (TG), Spiral Ganglion (SG) and Dorsal Root Ganglion (DRG) $[10,30,31,41,44,74,76,91,106,112]$, and their functions are mediated at least in part through regulation of neurotrophic receptors. In the $B r n 3 a^{K O / K O} \mathrm{TG}, \operatorname{TrkC}$ 
expression is essentially lost from onset (E10.5), while TrkA and TrkB are initially (E10.5) expressed but turn off at E15.5, followed by extensive cell death in the TG. By E17, only $30 \%$ of $B r n 3 a^{K O / K O}$ TG neurons survive, a majority of which express the Ret receptor [44]. These changes in neurotrophin receptors are accompanied by significant shifts in cell type distribution [48, 50-52]. In the spiral (acoustic) ganglion of $\mathrm{Brn} 3 \mathrm{a}^{K O / K O}$ mice TrkC is downregulated resulting in dendritic arbor abnormalities [41]. Brn3a loss of function also affects cell type distributions in a variety of DRG cell types [47, $49,53,54$ ], accompanied by dynamic changes in numbers of Trk $A$, TrkB and TrkC receptors, and increase in Ret $^{+}$cell numbers [112]. Significantly, in DRGs, Brn3a is a direct transcriptional regulator of TrkA [69], while in RGCs Brn3a loss may modestly affect TrkA expression levels $[78,92]$. In the retina, some TFs are shown to modulate neurotrophic signaling components. For instance, Dlx2, a known activator of Brn3b [110], also directly regulates TrkB receptor expression in RGCs [29]. Conversely, instances of control of TFs by neurotrophins were documented in motor and sensory systems. Dendritic branching and connectivity of a subset of motor neurons in spinal cord is controlled by a TF encoded by the Pea3 gene, which is in turn induced by target derived GDNF signaling [102]. In DRGs, GDNF activates a transcriptional program repressing neurite growth of sensory neurons [63].

Surprisingly, not much is known about Ret and Trk control of cell type specification and dendrite formation in RGCs. Gain and loss of function manipulations of the BDNF/NT4 - TrkB axis in mice and frogs did not result in RGC loss, however produced a range of phenotypes including changes in dendritic arbor formation and RGC axon shifts towards small diameter fibers $[17,25,89]$.

We now show that Ret, GFR $\alpha$ and Trk receptors expression in RGCs is partially overlapping and can be modulated by Brn3 transcription factors ([78, 92] Figs. 8, 9 and 10, and Supplementary Figs. 1, 2, 3, 4 and 5). In our hands, the numbers of Ret ${ }^{\mathrm{CFP}}$, Brn3a and Brn3bexpressing RGCs are transiently altered during development but largely unaffected in $\operatorname{Ret}^{K O / K O}$ (Ret ${ }^{\text {CFP/CFP }}$ ) mice relative to control animals. While our previous RNAseq experiments did not show a significant Brn3adependency of Ret gene expression in early postnatal age $[85,92]$, we now find that in adults, Ret expression in the retina-specific Brn3a knockout is moderately but significantly altered. The partial redistribution of double positive $\left(\operatorname{Ret}^{+} \mathrm{AP}^{+}\right)$in controls to single $\left(\operatorname{Ret}^{+}\right)$cells in $B r n 3 a^{K O / K O}$ retinas may be due to the loss of some $\left(\mathrm{Brn}^{2} \mathrm{a}^{+} \operatorname{Ret}^{+}\right)$-expressing neurons such as $\mathrm{ON}$ and OFF $\beta$ and ON spiny RGCs. When compared to the wild type, $B r n 3 a^{A P / K O}$ retinas exhibit a significant increase in $\mathrm{GFR} \alpha 1^{+}, \mathrm{GFR} \alpha 2^{+}$and GFR $\alpha 3^{+}$cells in the GCL, at the expense of Brn3a ${ }^{A P}$ RGCs, potentially indicating that Brn3a expression suppresses Ret-GFR $\alpha$ expression in certain RGC types (or displaced amacrine cells), leading to choices in cell type specification or morphological features of dendritic arbors. On the contrary, numbers of $\operatorname{Trk} \mathrm{A}^{+} \mathrm{Brn}_{3} \mathrm{a}^{\mathrm{AP}}$ and $\operatorname{Trk} \mathrm{C}^{+} \mathrm{Brn}_{3} \mathrm{a}^{\mathrm{AP}}$ RGCs are somewhat reduced in $B r n 3 a^{A P / K O}$ compared to $B r n 3 a^{A P / W T}$ retinas, while $\operatorname{TrkA}^{+}$and $\operatorname{TrkC}^{+}$cell numbers in the GCL are increased. By analogy with the TGG and DRG systems, these shifts could induce alternative RGC cell type decisions.

\section{Conclusions}

Taken together, our data suggest that, in the sparsely recombined Ret ${ }^{\mathrm{CreERt} 2 / \mathrm{WT}}$; Brn3a ${ }^{\mathrm{AP} / \mathrm{WT}}$ and Ret ${ }^{\mathrm{CreERt} 2 /}$ ${ }^{W T}$; Brn3a ${ }^{A P / K O}$ RGCs, the dosage reduction of Brn3a affects the expression of signaling components of the Ret (Ret, GFR $\alpha 1-3$ or downstream signaling molecules) and/or Trk pathway. These subtle transcriptional effects combined with Ret heterozygosity result in shifts in cell type specification or morphological defects. Ret can function as a competitive coreceptor for ligands involved in neuronal arbor formation and axon guidance, such as ephrin and p75-NTR [14] and Plexin / NCAMs [20], some of which are under transcriptional control of Brn3a $[78,92]$. Thus, it is possible that the reduced Brn3a dosage in Ret ${ }^{\mathrm{CreERt} 2 / \mathrm{WT}} ; \mathrm{Brn} \mathrm{a}^{\mathrm{AP} / \mathrm{WT}}$ and $\mathrm{Ret}^{\mathrm{CreER} 2 / \mathrm{WT}}$; Brn3a ${ }^{\mathrm{AP} / \mathrm{KO}} \mathrm{RGCs}$ results in partial loss of these co-receptors, and consequentially in morphological defects.

The proposed competitive nature of the Ret Brn3a genetic interaction in the context of RGC specification could read out signals necessary to specify the appropriate numbers and spacing of distinct RGC types. Since both Ret and Brn3a are postmitotically expressed in RGCs, this could mean that RGC type fate is still plastic after exiting the cell cycle, as has been proposed for photoreceptors [1, 23, 79, 97]. This mechanism could then explain how individual retinal clones originating early in retinal development can adjust their composition to accommodate the diversity of RGC type distribution and density, by shifting cell type specificity according to local neurotrophic signaling originating from other already specified RGC types. Alternatively, target derived neurotrophic support could help eliminate excess RGCs, by engaging either Ret-GFR $\alpha$ or TrkA$\mathrm{C}$ signaling in an activity and/or Brn3a dependent manner. Intriguingly, Ret ligands GDNF and Neurturin, and Trk ligands BDNF, NGF and NT3 are differentially expressed at relevant developmental 
stages in other retinal neurons, RGCs themselves and/or retinorecipient brain areas (Sajgo, 2017 and Supplementary Figs. 1 and 4). It will remain to explore which of these sources are relevant in the competitive mechanism we propose.

\section{Supplementary Information}

The online version contains supplementary material available at https://doi. org/10.1186/s13064-021-00155-z.

Additional file 1: Supplementary Figure 1 Expression of Glial Derived Neurotrophin Ligands and their receptors in E15 and P3 RGCs and major retinorecipient areas of the brain.

Additional file 2: Supplementary Figure 2. Significant developmental overlap of Brn3a, Ret, and its coreceptors GFRa2 and GFRa3.

Additional file 3: Supplementary Figure 3. Ret signaling downstream targets are expressed in Brn3a+ RGCs.

Additional file 4: Supplementary Figure 4. Expression of Target Derived Neurotrophin Ligands and their receptors in E15 and P3 RGCs and major retinorecipient areas of the brain.

Additional file 5: Supplementary Figure 5. Full retinal Brn3a KO mildly affects distribution of Trk receptors in RGCs

Additional file 6: Supplementary Table 1. $x^{2}$ statistics for pair-wise comparisons between different sparse random recombination experimental groups (age and genotype) considering RGC subtype distribution

Additional file 7: Supplementary Table 2.

Additional file 8: Supplementary Table 3.

\section{Acknowledgements}

Wenqin Luo - U. Pennsylvania and Hideki Enomoto - Kobe University for helpful comments and providing mouse lines. Nadia Parmhans for assistance with Genotyping.

\section{Authors' contributions}

V.M. and T.C.B. designed experiments, prepared figures and wrote Manuscript. V.M. performed all experiments and collected all data. The author(s) read and approved the final manuscript.

\section{Funding}

To T.C.B from the National Eye Institute via intramural funding: Retinal Circuit Development \& Genetics Unit, Project number 1ZIAEY000504. Open Access funding provided by the National Institutes of Health $(\mathrm{NIH})$.

\section{Availability of data and materials}

All data related to this manuscript will be made available upon request from the corresponding authors.

\section{Declarations}

Ethics approval and consent to participate

Not applicable (animal procedure approval is stated in the relevant section of material and methods).

\section{Consent for publication}

All authors consent to publication.

\section{Competing interests}

The authors declare no competing interests.

\section{Author details}

${ }^{1}$ Retinal Circuit Development \& Genetics Unit, Neurobiology-Neurodegeneration \& Repair Laboratory, National Eye Institute, NIH, Bethesda, MD, USA. ${ }^{2}$ Institute of Cytology and Genetics, Novosibirsk State University, Novosibirsk,
Russia. ${ }^{3}$ Research and Development Institute, School of Medicine, Transilvania University of Brasov, Brasov, Romania.

Received: 19 April 2021 Accepted: 5 August 2021

Published online: 21 September 2021

\section{References}

1. Adler R, Hatlee M. Plasticity and differentiation of embryonic retinal cells after terminal mitosis. Science. 1989;243:391-3.

2. Airaksinen MS, Saarma M. The GDNF family: signalling, biological functions and therapeutic value. Nat Rev Neurosci. 2002;3:383-94.

3. Amthor FR, Oyster CW, Takahashi ES. Morphology of on-off directionselective ganglion cells in the rabbit retina. Brain Res. 1984;298:187-90.

4. Avantaggiato V, Dathan NA, Grieco M, et al. Developmental expression of the RET protooncogene. Cell Growth Differ. 1994;5:305-11.

5. Badea TC, Cahill H, Ecker J, et al. Distinct roles of transcription factors brn3a and brn3b in controlling the development, morphology, and function of retinal ganglion cells. Neuron. 2009;61:852-64.

6. Badea TC, Hua ZL, Smallwood PM, et al. New mouse lines for the analysis of neuronal morphology using CreER(T)/loxP-directed sparse labeling. PLoS One. 2009;4:e7859.

7. Badea TC, Nathans J. Morphologies of mouse retinal ganglion cells expressing transcription factors Brn3a, Brn3b, and Brn3c: analysis of wild type and mutant cells using genetically-directed sparse labeling. Vision Res. 2011;51:269-79.

8. Badea TC, Nathans J. Quantitative analysis of neuronal morphologies in the mouse retina visualized by using a genetically directed reporter. J Comp Neurol. 2004;480:331-51.

9. Badea TC, Wang Y, Nathans J. A noninvasive genetic/pharmacologic strategy for visualizing cell morphology and clonal relationships in the mouse. J Neurosci. 2003;23:2314-22.

10. Badea TC, Williams J, Smallwood P, et al. Combinatorial expression of Brn3 transcription factors in somatosensory neurons: genetic and morphologic analysis. J Neurosci. 2012;32:995-1007.

11. Baden T, Berens P, Franke $K$, et al. The functional diversity of retinal ganglion cells in the mouse. Nature. 2016;529:345-50.

12. Bae JA, Mu S, Kim JS, et al. Digital Museum of Retinal Ganglion Cells with Dense Anatomy and Physiology. Cell. 2018;173:1293-1306 e1219.

13. Berson DM, Pu M, Famiglietti EV. The zeta cell: a new ganglion cell type in cat retina. J Comp Neurol. 1998;399:269-88.

14. Bonanomi D, Chivatakarn O, Bai G, et al. Ret is a multifunctional coreceptor that integrates diffusible- and contact-axon guidance signals. Cell. 2012;148:568-82.

15. Brantley MA Jr, Jain S, Barr EE, et al. Neurturin-mediated ret activation is required for retinal function. J Neurosci. 2008;28:4123-35.

16. Brown NL, Kanekar S, Vetter ML, et al. Math5 encodes a murine basic helix-loop-helix transcription factor expressed during early stages of retinal neurogenesis. Development. 1998;125:4821-33.

17. Cellerino A, Carroll $P$, Thoenen $H$, et al. Reduced size of retinal ganglion cell axons and hypomyelination in mice lacking brain-derived neurotrophic factor. Mol Cell Neurosci. 1997;9:397-408.

18. Cellerino A, Kohler K. Brain-derived neurotrophic factor/neurotrophin-4 receptor TrkB is localized on ganglion cells and dopaminergic amacrine cells in the vertebrate retina. J Comp Neurol. 1997;386:149-60.

19. Chao MV. Neurotrophins and their receptors: a convergence point for many signalling pathways. Nat Rev Neurosci. 2003;4:299-309.

20. Charoy C, Nawabi H, Reynaud F, et al. gdnf activates midline repulsion by Semaphorin3B via NCAM during commissural axon guidance. Neuron. 2012;75:1051-66.

21. Chen Al, De Nooij JC, Jessell TM. Graded activity of transcription factor Runx3 specifies the laminar termination pattern of sensory axons in the developing spinal cord. Neuron. 2006:49:395-408.

22. Chen C-L, Broom DC, Liu Y, et al. RunX1 determines nociceptive sensory neuron phenotype and is required for thermal and neuropathic pain. Neuron. 2006:49:365-77.

23. Cheng $\mathrm{H}$, Aleman TS, Cideciyan AV, et al. In vivo function of the orphan nuclear receptor NR2E3 in establishing photoreceptor identity during mammalian retinal development. Hum Mol Genet. 2006;15:2588-602. 
24. Cohen-Cory S, Escandon E, Fraser SE. The cellular patterns of BDNF and trkB expression suggest multiple roles for BDNF during Xenopus visual system development. Dev Biol. 1996;179:102-15.

25. Cohen-Cory S, Fraser SE. Effects of brain-derived neurotrophic factor on optic axon branching and remodelling in vivo. Nature. 1995;378:192-6.

26. Conway JA, Ince S, Black S, et al. GDNF/RET signaling in dopamine neurons in vivo. Cell Tissue Res. 2020;382:135-46.

27. Coombs J, Van Der List D, Wang G-Y, et al. Morphological properties of mouse retinal ganglion cells. Neuroscience. 2006;140:123-36.

28. Dacey DM, Lee BB. The "blue-on" opponent pathway in primate retina originates from a distinct bistratified ganglion cell type. Nature. 1994;367:731-5.

29. De Melo J, Zhou QP, Zhang Q, et al. Dlx2 homeobox gene transcriptional regulation of Trkb neurotrophin receptor expression during mouse retinal development. Nucleic Acids Res. 2008;36:872-84.

30. Dykes IM, Lanier J, Eng SR, et al. Brn3a regulates neuronal subtype specification in the trigeminal ganglion by promoting Runx expression during sensory differentiation. Neural Dev. 2010;5:3.

31. Dykes IM, Tempest L, Lee SI, et al. Brn3a and Islet1 act epistatically to regulate the gene expression program of sensory differentiation. J Neurosci. 2011;31:9789-99.

32. Ecker JL, Dumitrescu ON, Wong KY, et al. Melanopsin-expressing retinal ganglion-cell photoreceptors: cellular diversity and role in pattern vision. Neuron. 2010:67:49-60.

33. Enokido Y, De Sauvage F, Hongo JA, et al. GFR alpha-4 and the tyrosine kinase Ret form a functional receptor complex for persephin. Curr Biol. 1998;8:1019-22.

34. Enomoto H, Crawford PA, Gorodinsky A, et al. RET signaling is essential for migration, axonal growth and axon guidance of developing sympathetic neurons. Development. 2001;128:3963-74.

35. Erkman L, Mcevilly RJ, Luo L, et al. Role of transcription factors Brn-3.1 and Brn-3.2 in auditory and visual system development. Nature. 1996;381:603-6.

36. Ernsberger U. The role of GDNF family ligand signalling in the differentiation of sympathetic and dorsal root ganglion neurons. Cell Tissue Res. 2008:333:353-71.

37. Ernsberger $U$. Role of neurotrophin signalling in the differentiation of neurons from dorsal root ganglia and sympathetic ganglia. Cell Tissue Res. 2009;336:349-84.

38. Gan $L$, Xiang $M$, Zhou $L$, et al. POU domain factor Brn-3b is required for the development of a large set of retinal ganglion cells. Proc Natl Acad Sci U S A. 1996;93:3920-5.

39. Golden JP, Hoshi M, Nassar MA, et al. RET signaling is required for survival and normal function of nonpeptidergic nociceptors. J Neurosci. 2010;30:3983-94.

40. Helmstaedter M, Briggman KL, Turaga SC, et al. Connectomic reconstruction of the inner plexiform layer in the mouse retina. Nature. 2013;500:168-74.

41. Huang EJ, Liu W, Fritzsch B, et al. Brn3a is a transcriptional regulator of soma size, target field innervation and axon pathfinding of inner ear sensory neurons. Development. 2001;128:2421-32.

42. Huang EJ, Reichardt LF. Neurotrophins: roles in neuronal development and function. Annu Rev Neurosci. 2001;24:677-736.

43. Huang EJ, Reichardt LF. Trk receptors: roles in neuronal signal transduction. Annu Rev Biochem. 2003;72:609-42.

44. Huang EJ, Zang K, Schmidt A, et al. POU domain factor Brn-3a controls the differentiation and survival of trigeminal neurons by regulating Trk receptor expression. Development. 1999;126:2869-82.

45. Huang L, Hu F, Xie X, et al. Pou4f1 and pou4f2 are dispensable for the long-term survival of adult retinal ganglion cells in mice. PLoS One. 2014;9:e94173.

46. Huberman AD, Wei W, Elstrott J, et al. Genetic identification of an On-Off direction-selective retinal ganglion cell subtype reveals a layer-specific subcortical map of posterior motion. Neuron. 2009;62:327-34.

47. Ichikawa $\mathrm{H}, \mathrm{Mo} Z$, Xiang $\mathrm{M}$, et al. Brn-3a deficiency increases tyrosine hydroxylase-immunoreactive neurons in the dorsal root ganglion. Brain Res. 2005;1036:192-5.

48. Ichikawa $\mathrm{H}, \mathrm{Mo} Z$, Xiang $M$, et al. Effect of Brn-3a deficiency on nociceptors and low-threshold mechanoreceptors in the trigeminal ganglion. Brain Res Mol Brain Res. 2002;104:240-5.
49. Ichikawa $H, M o Z$, Xiang M, et al. Effect of Brn-3a deficiency on parvalbumin-immunoreactive primary sensory neurons in the dorsal root ganglion. Brain Res Dev Brain Res. 2004;150:41-5.

50. Ichikawa H, Qiu F, Xiang M, et al. Brn-3a is required for the generation of proprioceptors in the mesencephalic trigeminal tract nucleus. Brain Res. 2005;1053:203-6.

51. Ichikawa H, Schulz S, Hollt V, et al. Effect of Brn-3a deficiency on primary nociceptors in the trigeminal ganglion. Neurosci Res. 2005;51:445-51.

52. Ichikawa H, Terayama R, Yamaai T, et al. Brn-3a deficiency transiently increases expression of calbindin D-28 $\mathrm{k}$ and calretinin in the trigeminal ganglion during embryonic development. Cell Mol Neurobiol. 2009;29:691-8.

53. Ichikawa H, Yamaai T, Jacobowitz DM, et al. Effect of Brn-3a deficiency on parvalbumin-, calbindin D-28k-, calretinin- and calcitonin generelated peptide-immunoreactive primary sensory neurons in the trigeminal ganglion. Neuroscience. 2002;113:537-46.

54. Ichikawa H, Yamaai T, Mo Z, et al. Effect of Brn-3a deficiency on CGRP-immunoreactivity in the dorsal root ganglion. NeuroReport. 2002;13:409-12.

55. Jacoby J, Schwartz GW. Three Small-Receptive-Field Ganglion Cells in the Mouse Retina Are Distinctly Tuned to Size, Speed, and Object Motion. J Neurosci. 2017;37:610-25.

56. Johnson KP, Zhao L, Kerschensteiner D. A Pixel-Encoder Retinal Ganglion Cell with Spatially Offset Excitatory and Inhibitory Receptive Fields. Cell Rep. 2018;22:1462-72.

57. Joo W, Hippenmeyer S, Luo L. Neurodevelopment. Dendrite morphogenesis depends on relative levels of NT-3/TrkC signaling. Science. 2014;346:626-9.

58. Kawai K, Takahashi M. Intracellular RET signaling pathways activated by GDNF. Cell Tissue Res. 2020;382:113-23.

59. Klimova L, Lachova J, Machon O, et al. Generation of mRx-Cre transgenic mouse line for efficient conditional gene deletion in early retinal progenitors. PLoS One. 2013;8:e63029.

60. Kramer I, Sigrist M, De Nooij JC, et al. A role for Runx transcription factor signaling in dorsal root ganglion sensory neuron diversification. Neuron. 2006:49:379-93.

61. Krieger B, Qiao M, Rousso DL, et al. Four alpha ganglion cell types in mouse retina: Function, structure, and molecular signatures. PLoS One. 2017;12:e0180091.

62. Lim YS, Mclaughlin T, Sung TC, et al. p75(NTR) mediates ephrin-A reverse signaling required for axon repulsion and mapping. Neuron. 2008;59:746-58.

63. Linnarsson S, Mikaels A, Baudet C, et al. Activation by GDNF of a transcriptional program repressing neurite growth in dorsal root ganglia. Proc Natl Acad Sci U S A. 2001;98:14681-6.

64. Liu W, Mo Z, Xiang M. The Ath5 proneural genes function upstream of Brn3 POU domain transcription factor genes to promote retinal ganglion cell development. Proc Natl Acad Sci U S A. 2001;98:1649-54

65. Liu X, Robinson ML, Schreiber AM, et al. Regulation of neonatal development of retinal ganglion cell dendrites by neurotrophin-3 overexpression. J Comp Neurol. 2009;514:449-58.

66. Llamosas MM, Cernuda-Cernuda R, Huerta JJ, et al. Neurotrophin receptors expression in the developing mouse retina: an immunohistochemical study. Anat Embryol (Berl). 1997;195:337-44.

67. Luo W, Enomoto H, Rice FL, et al. Molecular identification of rapidly adapting mechanoreceptors and their developmental dependence on ret signaling. Neuron. 2009;64:841-56.

68. Luo W, Wickramasinghe SR, Savitt JM, et al. A hierarchical NGF signaling cascade controls Ret-dependent and Ret-independent events during development of nonpeptidergic DRG neurons. Neuron. 2007:54:739-54

69. Ma L, Lei L, Eng SR, et al. Brn3a regulation of TrkA/NGF receptor expression in developing sensory neurons. Development. 2003;130:3525-34.

70. Mani A, Schwartz GW. Circuit Mechanisms of a Retinal Ganglion Cell with Stimulus-Dependent Response Latency and Activation Beyond Its Dendrites. Curr Biol. 2017:27:471-82.

71. Marler KJ, Poopalasundaram S, Broom ER, et al. Pro-neurotrophins secreted from retinal ganglion cell axons are necessary for ephrinA-p75NTR-mediated axon guidance. Neural Dev. 2010;5:30. 
72. Marler KJ, Suetterlin P, Dopplapudi A, et al. BDNF promotes axon branching of retinal ganglion cells via miRNA-132 and p250GAP. J Neurosci. 2014;34:969-79.

73. Marler KJM, Becker-Barroso E, Martínez A, et al. A TrkB/EphrinA interaction controls retinal axon branching and synaptogenesis. J Neurosci. 2008;28:12700-12.

74. Marmigere F, Ernfors P. Specification and connectivity of neuronal subtypes in the sensory lineage. Nat Rev Neurosci. 2007;8:114-27.

75. Masland $\mathrm{RH}$. The neuronal organization of the retina. Neuron. 2012;76:266-80

76. Mcevilly RJ, Erkman L, Luo L, et al. Requirement for Brn-3.0 in differentiation and survival of sensory and motor neurons. Nature. 1996:384:574-7.

77. Morgan JL, Dhingra A, Vardi N, et al. Axons and dendrites originate from neuroepithelial-like processes of retinal bipolar cells. Nat Neurosci. 2006;9:85-92

78. Muzyka W, Brooks M, Badea TC. Postnatal developmental dynamics of cell type specification genes in Brn3a/Pou4f1 Retinal Ganglion Cells. Neural Dev. 2018;13:15.

79. $\mathrm{Ng} \mathrm{L}$, Lu A, Swaroop A, et al. Two transcription factors can direct three photoreceptor outcomes from rod precursor cells in mouse retinal development. J Neurosci. 2011;31:11118-25.

80. Nomoto S, Ito S, Yang LX, et al. Molecular cloning and expression analysis of GFR alpha-3, a novel cDNA related to GDNFR alpha and NTNR alpha. Biochem Biophys Res Commun. 1998;244:849-53.

81. Ohgami N, Ida-Eto M, Shimotake T, et al. c-Ret-mediated hearing loss in mice with Hirschsprung disease. Proc Natl Acad Sci U S A 2010;107:13051-6.

82. Pachnis V, Mankoo B, Costantini F. Expression of the c-ret proto-oncogene during mouse embryogenesis. Development. 1993;119:1005-17.

83. Pan $L$, Yang Z, Feng $L$, et al. Functional equivalence of Brn3 POU-domain transcription factors in mouse retinal neurogenesis. Development 2005;132:703-12.

84. Pang J-J, Gao F, Wu SM. Light-evoked excitatory and inhibitory synaptic inputs to ON and OFF alpha ganglion cells in the mouse retina. J Neurosci. 2003;23:6063-73.

85. Parmhans N, Sajgo S, Niu J, et al. Characterization of retinal ganglion cell, horizontal cell, and amacrine cell types expressing the neurotrophic receptor tyrosine kinase Ret. J Comp Neurol. 2018;526:742-66.

86. Puller C, Manookin MB, Neitz J, et al. Broad thorny ganglion cells: a candidate for visual pursuit error signaling in the primate retina. J Neurosci. 2015;35:5397-408.

87. Rheaume BA, Jereen A, Bolisetty M, et al. Single cell transcriptome profiling of retinal ganglion cells identifies cellular subtypes. Nat Commun. 2018;9:2759.

88. Rivlin-Etzion M, Zhou K, Wei W, et al. Transgenic mice reveal unexpected diversity of on-off direction-selective retinal ganglion cell subtypes and brain structures involved in motion processing. J Neurosci. 2011;31:8760-9.

89. Rohrer B, Lavail MM, Jones KR, et al. Neurotrophin receptor TrkB activation is not required for the postnatal survival of retinal ganglion cells in vivo. Exp Neurol. 2001;172:81-91.

90. Rousso DL, Qiao M, Kagan RD, et al. Two Pairs of ON and OFF Retinal Ganglion Cells Are Defined by Intersectional Patterns of Transcription Factor Expression. Cell Rep. 2016;15:1930-44.

91. Sajgo S, Ali S, Popescu O, et al. Dynamic expression of transcription factor Brn3b during mouse cranial nerve development. Journal of Comparative Neurology. 2016;524:1033-61.

92. Sajgo S, Ghinia MG, Brooks M, et al. Molecular codes for cell type specification in Brn3 retinal ganglion cells. Proc Natl Acad Sci U S A. 2017;114:E3974-83.

93. Shi M, Kumar SR, Motajo O, et al. Genetic interactions between Brn3 transcription factors in retinal ganglion cell type specification. PLoS One. 2013;8:e76347.
94. Sonoda T, Okabe Y, Schmidt TM. Overlapping morphological and functional properties between M4 and M5 intrinsically photosensitive retinal ganglion cells. J Comp Neurol. 2020;528:1028-40. https://doi. org/10.1002/cne.24806

95. Stabio ME, Sabbah S, Quattrochi LE, et al. The M5 cell: a color-opponent intrinsically photosensitive retinal ganglion cell. Neuron. 2018;97:150163 e154.

96. Sumbul U, Song S, Mcculloch K, et al. A genetic and computational approach to structurally classify neuronal types. Nat Commun. 2014;5:3512.

97. Swaroop A, Kim D, Forrest D. Transcriptional regulation of photoreceptor development and homeostasis in the mammalian retina. Nat Rev Neurosci. 2010;11:563-76.

98. Tien NW, Pearson JT, Heller CR, et al. Genetically identified suppressedby-contrast retinal ganglion cells reliably signal self-generated visual stimuli. J Neurosci. 2015;35:10815-20.

99. Trupp M, Raynoschek C, Belluardo N, et al. Multiple GPI-anchored receptors control GDNF-dependent and independent activation of the c-Ret receptor tyrosine kinase. Mol Cell Neurosci. 1998;11:47-63.

100. Uesaka T, Nagashimada M, Yonemura S, et al. Diminished Ret expression compromises neuronal survival in the colon and causes intestinal aganglionosis in mice. J Clin Investig. 2008;118:1890-8.

101. Van Wyk M, Wassle H, Taylor WR. Receptive field properties of ON- and OFF-ganglion cells in the mouse retina. Vis Neurosci. 2009;26:297-308.

102. Vrieseling $\mathrm{E}$, Arber $\mathrm{S}$. Target-induced transcriptional control of dendritic patterning and connectivity in motor neurons by the ETS gene Pea3. Cell. 2006;127:1439-52.

103. Wang SW, Kim BS, Ding K, et al. Requirement for math5 in the development of retinal ganglion cells. Genes Dev. 2001;15:24-9.

104. Weng S, Sun W, He S. Identification of ON-OFF direction-selective ganglion cells in the mouse retina. J Physiol. 2005;562:915-23.

105. Xiang M, Gan L, Li D, et al. Essential role of POU-domain factor Brn-3C in auditory and vestibular hair cell development. Proc Natl Acad Sci U S A. 1997;94:9445-50.

106. Xiang M, Gan L, Zhou L, et al. Targeted deletion of the mouse POU domain gene Brn-3a causes selective loss of neurons in the brainstem and trigeminal ganglion, uncoordinated limb movement, and impaired suckling. Proc Natl Acad Sci U S A. 1996;93:11950-5.

107. Xiang M, Zhou L, Macke JP, et al. The Brn-3 family of POU-domain factors: primary structure, binding specificity, and expression in subsets of retinal ganglion cells and somatosensory neurons. J Neurosci. 1995;15:4762-85.

108. Yonehara K, Ishikane $H$, Sakuta $H$, et al. Identification of retinal ganglion cells and their projections involved in central transmission of information about upward and downward image motion. PLoS One. 2009:4:e4320.

109. Yonehara K, Shintani T, Suzuki R, et al. Expression of SPIG1 reveals development of a retinal ganglion cell subtype projecting to the medial terminal nucleus in the mouse. PLoS ONE. 2008:3:e1533.

110. Zhang Q, Zagozewski J, Cheng S, et al. Regulation of Brn3b by DLX1 and $D L X 2$ is required for retinal ganglion cell differentiation in the vertebrate retina. Development. 2017;144:1698-711.

111. Zhang Y, Kim IJ, Sanes JR, et al. The most numerous ganglion cell type of the mouse retina is a selective feature detector. Proc Natl Acad Sci U S A. 2012;109:E2391-2398.

112. Zou M, Li S, Klein WH, et al. Brn3a/Pou4f1 regulates dorsal root ganglion sensory neuron specification and axonal projection into the spinal cord. Dev Biol. 2012;364:114-27.

\section{Publisher's Note}

Springer Nature remains neutral with regard to jurisdictional claims in published maps and institutional affiliations. 